\title{
POLÍTICAS PÚBLICAS DE GÊNERO NA EDUCAÇÃO: UMA ANÁLISE PARA O DESENVOLVIMENTO
}

\author{
PUBLIC GENDER POLICIES IN EDUCATION: \\ AN ANALYSIS FOR DEVELOPMENT \\ POLÍTICAS PÚBLICAS DE GÉNERO EN LA EDUCACIÓN: \\ UN ANÁLISIS PARA EL DESARROLLO
}

\author{
MIRIAM OLIVIA KNOPIK FERRAZ \\ https://orcid.org/0000-0002-3350-5502 / http://lattes.cnpq.br/4312339156293623 / m.okf@hotmail.com \\ Pontifícia Universidade Católica do Paraná - PUCPR. \\ Curitiba, PR, Brasil.
}

\begin{abstract}
NICOLAS ADDOR
https://orcid.org/0000-0001-7359-0273 / http://lattes.cnpq.br/6045103769724219 / nicolasaddor@gmail.com Pontifícia Universidade Católica do Paraná - PUCPR. Curitiba, PR, Brasil.
\end{abstract}

JosÉ OSÓRIO NASCIMENTO NETO https://orcid.org/0000-0002-1798-4603 / http://lattes.cnpq.br/1715929488515498 / osorio.nascimento@gmail.com Centro Universitário Autônomo do Brasil, UniBrasil.

Curitiba, PR, Brasil.

\begin{abstract}
RESUMO
O presente estudo busca demonstrar que as políticas públicas de gênero na educação são juridicamente, socialmente e politicamente necessárias. A metodologia utilizada é a lógica-dedutiva, com o enfoque na bibliografia especializada para mapeamento e compreensão do tema. Para tanto, estuda-se como se estruturam as políticas públicas na educação e a sua relação com as minorias sociais. Posteriormente, adentra-se especificamente nas Políticas Públicas de Gênero na educação, demonstrando as iniciativas já existentes e as críticas às mesmas. Por fim, defende-se a inclusão do estudo de gênero na educação como caminho para uma sociedade justa e igualitária. Analisa-se, para isso, diversos planos nacionais de desenvolvimento social. Defende-se que é plenamente possível, aceitável e desejável a implementação de uma educação que vise a discussão do gênero enquanto identidade, violência e discriminação, visando principalmente a transversalidade de uma sociedade preocupada com as reais mazelas vivenciadas hoje: as questões de gênero, etnia, raça, classe e deficiências.
\end{abstract}

Palavras-chave: Educação; Estudo de Gênero; Gênero; Políticas públicas.

\begin{abstract}
The present study seeks to demonstrate that public policies of gender in education are legally, socially and politically necessary. The methodology used is logic-deductive, with a focus on specialized bibliography for mapping and understanding the theme. In order to do so, it was studied how public policies in education are structured and their relationship with social minorities. Subsequently, the Gender Public Policies in education were specifically incorporated, demonstrating existing initiatives and criticisms. Finally, we advocate the inclusion of gender studies in education as a path to a just and egalitarian society. Several national plans for social development were analyzed. It is argued that it is fully possible, acceptable and desirable to implement an education that aims at the discussion of
\end{abstract}


ISSN 1981-3694

(DOI): $10.5902 / 1981369431721$

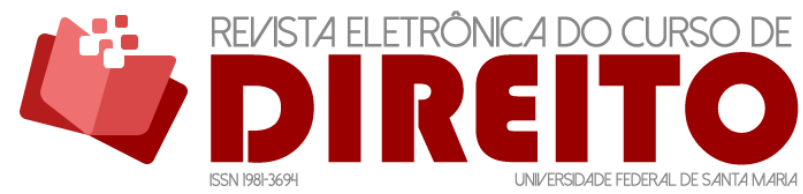

POLÍTICAS PÚBLICAS DE GÊNERO NA EDUCAÇÃO: UMA ANÁLISE PARA O DESENVOLVIMENTO

MIRIAM OLIVIA KNOPIK FERRAZ NICOLAS ADDOR JOSÉ OSÓRIO NASCIMENTO NETO

gender as identity, violence and discrimination, and aiming mainly at transversality of a society concerned with the real problems experienced today: issues of gender, ethnicity, race, class and disabilities.

Keywords: Education; Gender study; Gender; Public policy.

\section{RESUMEN}

Tradução do resumo para o espanhol. El estudio que se presenta busca demostrar que las políticas públicas de género en la educación son jurídicamente, social y políticamente necesarias. La metodología utilizada es la lógica-deductiva, con el enfoque en la bibliografía especializada para mapeamiento y comprensión del tema. Para ello, se estudió cómo se estructuran las políticas públicas en la educación y su relación con las minorías sociales. Más a delante, se adentró específicamente las Políticas Públicas de Género en la educación demostrando las iniciativas ya existentes y las críticas. Por último, se defiende la inclusión del estudio de género en la educación como medio para una sociedad justa e igualitaria. Se analizó diversos planes nacionales de desarrollo social. Se defiende que es plenamente posible, aceptable y deseable la ejecución de una educación que tenga como objetivo la discusión del género como identidad, violencia y discriminación, y, con el objetivo, principalmente la transversalidad de una sociedad preocupada por los reales males vivenciados hoy: las cuestiones de género, etnia, raza, clase y deficiencias.

Palabras clave: Educación; Estudio de Género; Género; Políticas públicas.

\section{SUMÁRIO}

INTRODUÇAO; 1 POLÍTICAS PÚBLICAS NA EDUCAÇÃO E MINORIAS; 2 POLÍTICAS PÚBLICAS DE GÊNERO NA EDUCAÇÃO; 2.1 Políticas públicas de gênero na educação: patamar atual; 2.2. Críticas às políticas públicas de inclusão ao estudo de gênero na educação; 3. A INCLUSÃO DO ESTUDO DE GÊNERO NA EDUCAÇÃO COMO CAMINHO PARA O DESENVOLVIMENTO; CONCLUSÃO; REFERÊNCIAS.

\section{INTRODUÇÃO}

As políticas públicas de gênero na educação vêm causando diversas controvérsias e discussões na sociedade, em específico ao estudo de gênero nas escolas. Entretanto, e como será demonstrado neste trabalho, a maioria das críticas se fundam em argumentos falaciosos e construídos para deslegitimar um movimento sério teórico-prático que busca a discussão das principais mazelas que afetam boa parte da sociedade: mulheres, homens, comunidade LGBTI+, negros, índios, pessoas com deficiência etc. Discutir gênero é trabalhar com a transversalidade e compreender que esses fatores podem estar combinados e gerar o acúmulo de preconceitos e discriminações, fatores que se busca combater com a educação.

Centraliza-se a problemática no questionamento: qual o fundamento para a inclusão do estudo de gênero na educação? A hipótese que se trabalha é a necessidade de se questionar os papéis sociais e utilizar de políticas públicas para formação de um ambiente de ensino diverso e plural.

Políticas públicas educacionais são de extrema importância para a formação e reestruturação de uma sociedade, uma vez que a escola e outros ambientes de ensino possuem o 
ISSN 1981-3694

(DOI): $10.5902 / 1981369431721$

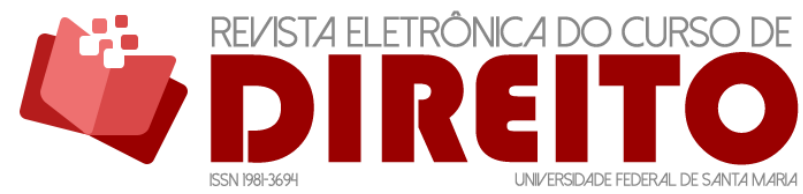

POLÍTICAS PÚBLICAS DE GÊNERO NA EDUCAÇÃO: UMA ANÁLISE PARA O DESENVOLVIMENTO

MIRIAM OLIVIA KNOPIK FERRAZ NICOLAS ADDOR JOSÉ OSÓRIO NASCIMENTO NETO

condão de formar (e deformar) o indivíduo nos moldes da sociedade em que vive, o que, de fato, deve ser orientado para "a sociedade em que se quer viver".

Para fins dessa pesquisa, utiliza-se a metodologia lógico-dedutiva, partindo-se da compreensão do tema geral da problemática envolvida, no que tange às Políticas Públicas e Minorias, traçando-se, posteriormente, as especificidades dos debates sobre o estudo de gênero na educação. Finalmente, por meio da comparação entre os argumentos favoráveis e contrários a tais estudos, aponta-se o estudo de gênero como um fator para o desenvolvimento.

Os objetivos do presente estudo serão apresentados nos seguintes tópicos: i. A estrutura das políticas públicas na educação e a sua relação com as minorias sociais; ii. 0 estudo das Políticas Públicas de Gênero na educação, demonstrando-se as iniciativas já existentes e as principais críticas à abordagem desse tema nas escolas; iii. A defesa da inclusão do estudo de gênero na educação como caminho para uma sociedade justa e igualitária, através da análise de alguns planos nacionais de desenvolvimento social: Plano Nacional de Políticas para Mulheres; Plano Nacional de Promoção da Igualdade Racial; Política Nacional de Promoção da Igualdade Racial; Plano Nacional dos Direitos da Pessoa com Deficiência, e; Plano Nacional de Educação. Ademais, analisam-se as propostas que podem contribuir diretamente com essa construção: o anteprojeto do Estatuto da Diversidade Sexual e de Gênero e o Currículo de Gênero, sob iniciativa da ONU Mulheres, em parceria com a iniciativa “O Valente não é violento".

Neste sentido, busca-se compreender as bases sociais que clamam por políticas públicas direcionadas a minorias e como elas devem ser desenvolvidas. 0 estudo de iniciativas já existentes contribui para mapear a abordagem atual sobre o tema e, inclusive, compreender como Políticas Públicas de educação de gênero podem auxiliar no desenvolvimento dos indivíduos em suas particularidades, bem como da sociedade em si.

\section{POLÍTICAS PÚBLICAS NA EDUCAÇÃO E MINORIAS ${ }^{1}$}

As Políticas Públicas em geral estão propostas como deveres do Estado por decorrência da estipulação de direitos fundamentais. A cláusula do Estado Social e Democrático de Direito

\footnotetext{
1 Atualmente, há duas concepções de "minorias": a primeira diz respeito ao elemento numérico e quantitativo, ou seja, é uma minoria (pequena parcela) da população ou do Estado-nação. Entretanto, neste estudo não é utilizada tal definição. A noção optada é a de minorias segundo o discurso jurídico e algumas concepções políticas, assim entendidas como "minorias sociais", ou seja, o conceito remete à parcela da população que é discriminada e possui pouco poder de voz. São exemplos dessas minorias as mulheres, os(as) negros(as), as pessoas LGBTI+, pessoas com deficiência, entre outros. VIANA, N. O que são minorias? Revista Posição, ano 3, v. 3, n. 9, jan-mar, 2016, p. 27-29.
} 
ISSN 1981-3694

(DOI): 10.5902/1981369431721

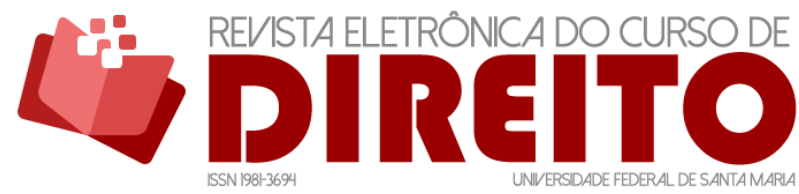

POLÍTICAS PÚBLICAS DE GÊNERO NA EDUCAÇÃO: UMA ANÁLISE PARA O DESENVOLVIMENTO

MIRIAM OLIVIA KNOPIK FERRAZ NICOLAS ADDOR JOSÉ OSÓRIO NASCIMENTO NETO

estende a proteção e dirige aos Poderes Públicos o dever de garantir aos cidadãos as condições mínimas e suficientes para uma vida digna, permitindo o desenvolvimento livre de sua personalidade. $^{2}$

Direcionando para uma conceituação, pode-se entender Política Pública como um conjunto de atos unificados que são ligados por um objetivo comum de empreender, ou mesmo prosseguir um projeto governamental para o país. ${ }^{3}$ Ela possui uma composição multidisciplinar, pois se exige a participação de outras áreas, como a sociologia, a ciência política, a antropologia e a economia, o que obriga qualquer teoria de política pública explicar as inter-relações entre Estado, política, economia e sociedade. ${ }^{4}$ Além disso, uma política pública pode sofrer controle judicial. $^{5}$

Complementando esse conceito, Vanice Regina Lírio do Valle elenca os elementos comuns que são encontrados nas diferentes escolas de Políticas Públicas, consideradas necessárias para a compreensão holística desse preceito. A autora enumera os seguintes pontos: as políticas públicas devem possuir distinção entre o que o Poder Público pretende fazer e o que realmente faz; a ciência de que todos os níveis de governo, e não apenas os autores formais, estão envolvidos numa Política Pública; uma Política Pública não está restrita aos instrumentos formais de regulação que envolvem um curso de ação intencional, com uma finalidade específica e conhecida como objetivo, e; por último, uma Política Pública também engloba um processo de desenvolvimento, que compreende não apenas a decisão de uma lei ou projeto, mas também as ações subsequentes de implementação, apoio e avaliação. ${ }^{6}$

Em relação à educação, a Constituição Federal categorizou expressamente no art.214 que o Estado deverá promover Políticas Públicas, com destaque para a erradicação do analfabetismo, a universalização do atendimento escolar, a melhoria da qualidade do ensino, a formação para o

2 GABARDO, E. Interesse público e subsidiariedade: o Estado e a sociedade civil para além do bem e do mal. Belo Horizonte: Fórum, 2009. p. 331.

3 MELLO, C. A. B. de. Curso de Direito Administrativo. 31. Ed. São Paulo: Malheiros, 2014, p. 832.

4 SOUZA, C. Políticas Públicas: uma revisão da literatura. Sociologias, Porto Alegre, ano 8, n. 16, juldez. 2006, p.20-46.

5 Neste ponto, Celso Antônio Bandeira de Mello complementa que "é inequívoco que se pode controlar juridicamente políticas públicas. Com efeito, se é possível controlar cada ato estatal, deve ser também possível controlar o todo e a movimentação rumo ao todo. Assim como agredir um princípio é mais grave que transgredir uma norma, empreender uma política - que é um plexo de atos - que seja em si mesma injurídica é mais grave que praticar um simples ato contraposto ao Direito. Logo, se é possível atacar o menos grave, certamente será possível atacar o mais grave". MELLO, C. A. B. de. Idem.

6 VALLE, V. R. L. do. Políticas públicas, direitos fundamentais e controle judicial. Belo Horizonte: Fórum, 2009, p.34. 
ISSN 1981-3694

(DOI): $10.5902 / 1981369431721$

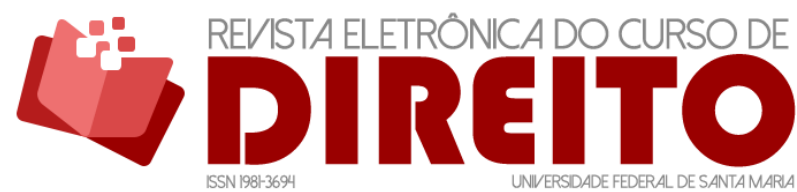

POLÍTICAS PÚBLICAS DE GÊNERO NA EDUCAC̄̃̃: UMA ANÁLISE PARA O DESENVOLVIMENTO

MIRIAM OLIVIA KNOPIK FERRAZ NICOLAS ADDOR JOSÉ OSÓRIO NASCIMENTO NETO

trabalho, a promoção humanística, científica e tecnológica do país e o estabelecimento de uma meta de aplicação de recursos públicos em educação.

Se a Carta Fundamental determinou objetivos para a evolução no ensino brasileiro, ela também ordenou a fixação de uma agenda de ação, com pauta primária de atuação e com proteção equiparada aos de âmbito constitucional, no que se concebe a denominada heterovinculação imposta ao poder político organizado. Uma heterovinculação pode se manifestar por três meios: como cláusulas impeditivas ao agir do poder; como deveres de conduta emanados da Constituição ou; como garantia de atuação reparadora do poder. ${ }^{7}$

Qualquer que seja a maneira de atuação sobre o sistema educacional brasileiro, quando é abordado o tema de Políticas Públicas, há neste ponto o que se denomina heterovinculação determinante de deveres de conduta. ${ }^{89}$ Sendo esta um dever de conduta imposto por um mandamento constitucional, diversas Políticas Públicas foram implementadas para democratizar o acesso e a manutenção no ensino (do primário ao superior), seja por meio de estabelecimento de cotas, de concessão de bolsas ou de empréstimos a juros reduzidos. A título exemplificativo, na educação superior, foram implementadas iniciativas como o Programa Universidade para todos - PROUNI, que concede bolsas de estudo em instituições privadas, o Programa nacional de acesso ao ensino técnico e emprego - PRONATEC, que democratiza e expande a oferta de cursos de educação profissional e tecnológica, ou mesmo o Fundo de Financiamento Estudantil - FIES, para financiar a graduação em instituições não gratuitas. Ainda enumerando exemplos, na educação básica existem atualmente dezoito programas, entre eles o Programa de Elevação da Escolaridade e qualificação profissional - Pro Jovem e o Programa Nacional de Alimentação Escolar.

Todas essas políticas vão ao encontro dos princípios que o serviço público da educação deve obedecer, com destaque para o princípio da generalidade. Se, por um lado, este princípio indica que os serviços públicos devem ser prestados com a maior amplitude possível, por outro, deve também beneficiar o maior número de indivíduos. ${ }^{10}$ De nada adianta o Poder Público

\footnotetext{
7 Idem, p.64.

8 Idem, p.65.

9 Vanice Regina Lírio do Valle complementa: “Assim é que a par da enunciação coercitiva, que exige o facere, é possível que preceitos constitucionais se alinhem com uma prática de propulsão ou incitação, ou ainda com uma orientação claramente distributiva, assegurando financiamento a uma determinada categoria da população. Finalmente, as normas que estabelecem heterovinculações podem ainda dedicarse ao desenho da estrutura institucional que promoverá aquela mesma atividade, ou ainda, sem traçar especificamente o referido contorno, sinalizar no sentido de um dever de atuação compartilhada, seja entre entes públicos, seja entre Administração e sociedade. DO VALLE. Idem, p.65-66.

10 CARVALHO FILHO, J. dos.S. Manual de Direito Administrativo. 31. Ed. São Paulo: Atlas, 2017, p.347.
} 
ISSN 1981-3694

(DOI): $10.5902 / 1981369431721$

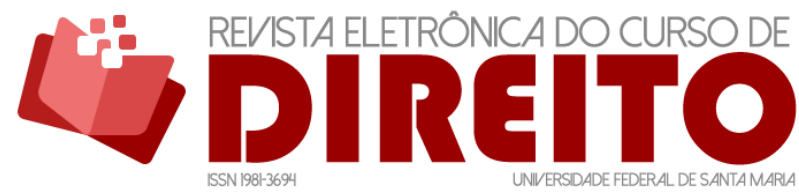

POLÍTICAS PÚBLICAS DE GÊNERO NA EDUCAÇÃO: UMA ANÁLISE PARA O DESENVOLVIMENTO

MIRIAM OLIVIA KNOPIK FERRAZ NICOLAS ADDOR JOSÉ OSÓRIO NASCIMENTO NETO

ofertar o serviço com qualidade e eficiência se o acesso a ele é dificultado pelas diferentes condições dos cidadãos. Por isso, um serviço público deve vir acompanhado de programas e diretrizes que busquem democratizar o acesso e criar mecanismos que possibilitem que o sujeito possa utilizá-lo.

Isso tem como causa a relação indissociável entre a Constituição e o Poder Público que torna o Estado um reflexo do desenvolvimento cultural da sociedade, com o equilíbrio entre o reconhecimento das conquistas históricas do passado e a projeção para um futuro a ser construído num modelo democrático, descrevendo um modelo ético que visa a redução por meio coletivo das desigualdades e a consagração de uma alteridade republicana, reflexo esse que foi adotado na Constituição Federal de $1988 .{ }^{11}$

Ademais, a ideia de construção de uma unidade democrática e de desenvolvimento nacional se encontra nos quatros objetivos fundamentais da República, no artigo terceiro da Constituição. Neste, a construção de uma sociedade livre, justa e igualitária, a garantia do desenvolvimento nacional, a erradicação da pobreza e da marginalização, com a redução das desigualdades sociais e regionais e a promoção do bem de todos, sem preconceito ou discriminação, denotam que o Estado deve garantir a gestão democrática do país.

Deste modo, fica evidenciado que há a responsabilidade do Estado em combater a desigualdade. O Poder Constituinte brasileiro demandou, assim, que haja uma preocupação com as minorias existentes no país. Por isso, entende-se que a educação de gênero e as Políticas Públicas de gênero são necessárias, com o intuito de democratizar o acesso à educação e a redução do preconceito e da discriminação, garantindo o amplo desenvolvimento da sociedade.

Sem embargo, tais políticas públicas de gênero devem possuir o escopo que se denomina "perspectiva transformativa de reconhecimento", ou seja, devem patrocinar o reconhecimento das identidades únicas de cada cidadã(o) e apoiar o respeito mútuo e a consideração. ${ }^{12}$

\section{POLÍTICAS PÚBLICAS DE GÊNERO NA EDUCAÇÃO}

O estudo de gênero consolidou-se no Brasil ao fim dos anos de 1970, em conjunto com o fortalecimento do feminismo. Entretanto, as Políticas Públicas não se desenvolveram de forma a abranger questões relativas ao objeto do estudo de gênero. ${ }^{13}$

11 GABARDO, E. Op. Cit.

12 AMARAL JÚNIOR, I. P. Educação para a diferença é um direito: a adequação constitucional das políticas públicas de combate à homofobia nas escolas. Dissertação (Mestrado em Direito) - Programa de Pós-Graduação em Direito, Estado e Constituição, Universidade de Brasília, Brasília, 2017, p.36-37. 
ISSN 1981-3694

(DOI): 10.5902/1981369431721

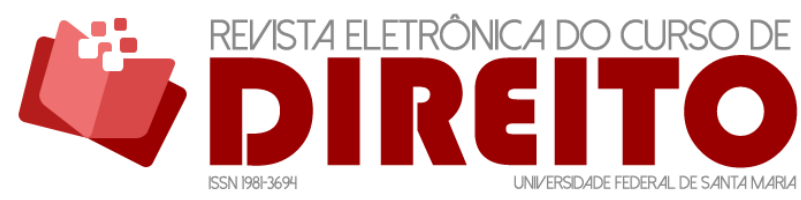

POLÍTICAS PÚBLICAS DE GÊNERO NA EDUCAÇÃO: UMA ANÁLISE PARA O DESENVOLVIMENTO

MIRIAM OLIVIA KNOPIK FERRAZ NICOLAS ADDOR JOSÉ OSÓRIO NASCIMENTO NETO

Apesar de o conceito advir de estudos e de lutas sociais feministas, este adquiriu diversas formas interpretativas, sendo destacados os feminismos da igualdade, da diferença e os pósestruturalistas. A base do feminismo da igualdade afirmava que as únicas diferenças entre homens e mulheres seriam as biológico-sexuais e as demais diferenças que poderiam ser observadas no cotidiano seriam culturais. ${ }^{14}$

Já os teóricos da diferença entendem que o conceito de gênero remeteria a traços culturais femininos, ou em oposição ao masculino, conceitos construídos através do social com base biológica. Assim, constrói-se a diferenciação binária como categoria central de análise e, através da diferença se pensariam e se formariam as estratégias de ação. ${ }^{15}$ Essa teoria possui o enfoque na polarização binária ampla: feminino e masculino; produção e reprodução, e; público e privado. Dessa forma, o poder estaria concentrado na esfera pública, sendo esta a origem da subordinação das mulheres. ${ }^{16}$

A teoria pós-estruturalista feminista tem como enfoque o caráter histórico e a construção social como bases para a percepção das diferenças de gênero. 0 destaque dessa teoria está em buscar quebrar a homogeneização ${ }^{17}$ presente no binarismo feminino e masculino, reconhecendo que a diversidade está em cada um e, assim, a análise iria ser composta por diversos outros marcadores como raça, classe e geração. ${ }^{18}$

Os conceitos de gênero, independente da abordagem, contribuem para a reflexão sobre as relações sociais entre os $\operatorname{sexos}^{19}$ e sobre as desigualdades entre os homens e mulheres como formas centrais do desequilíbrio do poder $^{20}$. Inclusive, possibilitam o debate mais amplo, considerando também a sexualidade e a transexualidade como pontos da influência social na construção de tipos, além do não reconhecimento de identidades.

13 FARAH, M. F. S. Gênero e Políticas Públicas. Revista Estudos Feministas. Florianópolis, UFSC, v. 12, n. 1, jan./abr. 2004a. p. 47-71.

14 CARVALHO, M. P. de. Gênero e trabalho decente: em busca de um referencial teórico. In: BRUSCHINI, C.; BUARQUE DE HOLLANDA, H. (Orgs.) Horizontes plurais: novos estudos de gênero no Brasil. São Paulo: Editora 34/ Fundação Carlos Chagas, 1998.

15 HITA, M. G. Gênero, ação e sistema: a reinvenção dos sujeitos. Lua nova, n. 43, p.109-131, 1998.

16 CARVALHO, M. P. Idem.

17 SCOTT, J. Prefácio a "Gender and Politics of History". Cadernos Pagu, Campinas, n.3, p.11-27, 1994; CARVALHO, M. P. de. Idem.

18 NICHOLSON, L. Interpreting gender. Sings: Journal of women in culture and society, Chicago, v.20, n.1, 1994, p.75-105.

19 FARAH, M. F. S. Op.cit., p. 47-71.

20 SAFFIOTI, H. I. B. Violência de gênero no Brasil contemporâneo. In: SAFFIOTTI, H. I. B.; MUÑOZVARGAS, M. (Orgs.) Mulher brasileira é assim. Rio de Janeiro/Brasília: Rosa dos Tempos - NIPAS/UNICEF, 1994, p.151-187. 
ISSN 1981-3694

(DOI): 10.5902/1981369431721

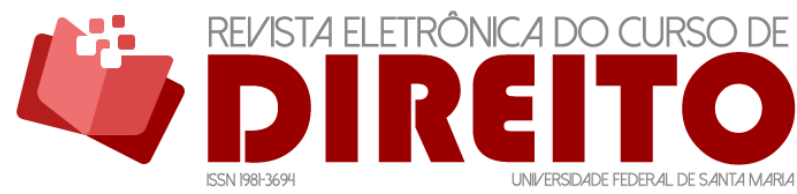

POLÍTICAS PÚBLICAS DE GÊNERO NA EDUCAÇÃO: UMA ANÁLISE PARA O DESENVOLVIMENTO

MIRIAM OLIVIA KNOPIK FERRAZ NICOLAS ADDOR JOSÉ OSÓRIO NASCIMENTO NETO

Importante ressaltar que "gênero" diz respeito à identidade da pessoa como homem, mulher, intersexual, transexual, transgênero. Tais identidades, principalmente quando enfocadas no binômio homem e mulher, são resultado das experiências e vivências das pessoas, ${ }^{21}$ ou seja, trata-se de um processo de práticas individuais que nunca se finaliza. ${ }^{22}$ Essas pessoas podem manifestar sua sexualidade de forma diversa, como homossexual, heterossexual, assexual, bissexual, dentre outros. ${ }^{23}$

As Políticas Públicas educacionais podem versar sobre quatro aspectos: capacitação laboral e acesso ao ensino básico e médio; reformulação de livros didáticos e conteúdos programáticos que traziam referências discriminatórias à mulher relacionadas à maternidade, como a ampliação de creches e pré-escolas; e a própria capacitação de professores para incluírem a perspectiva de gênero no processo educacional. ${ }^{24}$

Observa-se, entretanto, que Políticas Públicas educacionais com enfoque nas mulheres e na maternidade não necessariamente coadunam com os entendimentos dos feminismos supracitados. Por exemplo, a proposta do Ministério da Educação, no ano de 2003, da criação do Programa "Bolsa Primeira Infância"25, programa de bolsas para que as mulheres mães cuidassem de seus filhos de até três anos em casa, não onerando assim os cofres públicos em ampliar as vagas nas creches. Tal proposta contrapõe os dados do CENSO 2000 que demonstrou que apenas $10,6 \%$ das crianças de zero a três anos estão em escolas.

Tal fato pode se justificar por dois fundamentos. Qualquer Política Pública que visa a implementação de um tratamento diferenciado a um grupo específico, têm de ser diferenciada de conceitos puramente subjetivos que possam existir sobre o grupo. No entanto, é nítido que esses preconceitos podem influenciar nas políticas. ${ }^{26}$ Ademais, os incentivos e suas

21 Segundo Judith Butler gênero é um "projeto tácito para renovar a história cultural nas nossas próprias condições corpóreas; não é uma tarefa prescritiva de que devamos nos esforçar por fazer, mas aquela em que estamos nos esforçando sempre desde o começo". BUTLER, J. Variaçõ̃es sobre sexo e gênero. In: BENHABIB, S.; CORNELL, D. Feminismo como crítica da modernidade. Rio de Janeiro: Rosa dos tempos, 1987. p. 139-154.

22 MEYER, D. E. Gênero e Educação: teoria e política. In: LOURO, G. L.; FELIPE, J.; GOELLNER, S. V. (Orgs.). Corpo, gênero e sexualidade: um debate contemporâneo. 9. ed. Petrópolis: Vozes, 2013.

23 LOURO, Guacira Lopes. Gênero, sexualidade e educação: uma perspectiva pós-estruturalista. 16. ed. Petrópolis: Vozes, 2014.

24 FARAH, M. F. S. Op. cit.

25 ALBUQUERQUE, S. S. de Educação Infantil: um sonho a ser embalado? Grupo de Estudos em educação infantil e infâncias. Universidade Federal do Rio Grande do Sul, Porto Alegre, 2016. Disponível em: https://www.ufrgs.br/gein/wp-content/uploads/2016/10/Educa\%C3\%A7\%C3\%A3o-Infantil-um-sonho-aser-embalado.pdf. Acesso em: 10 out. 2017.

26 SOWELL, T. Ação afirmativa ao redor do mundo: um estudo empírico sobre cotas e grupos preferenciais. São Paulo: É Realizações, 2016. 
ISSN 1981-3694

(DOI): $10.5902 / 1981369431721$

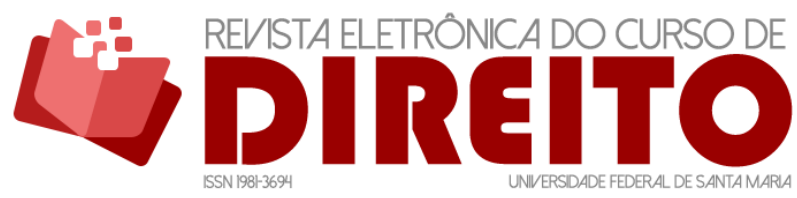

POLÍTICAS PÚBLICAS DE GÊNERO NA EDUCAÇÃO: UMA ANÁLISE PARA O DESENVOLVIMENTO

MIRIAM OLIVIA KNOPIK FERRAZ NICOLAS ADDOR JOSÉ OSÓRIO NASCIMENTO NETO

consequências tendem a ser ignorados nas discussões políticas de formulação da ação afirmativa, que focam somente nos motivos de sua implementação e nos benefícios presumidos, não considerando efeitos empíricos. ${ }^{27}$

Assim, as intersecções entre gênero e Políticas Públicas realmente começaram a aparecer de diversas formas, e obtiveram visibilidade nos estudos educacionais anos 1990, com o enfoque centralizado em políticas para redução da discriminação da mulher. ${ }^{28}$

Como destaca Silvana Aparecida Mariano, foi efetivamente no decorrer desta década, em especial em 1995, com a IV Conferência Mundial sobre a Mulher, promovida pela ONU, que este debate ganhou força e relevância, uma vez que se relacionou essas discussões entre gênero e Políticas Públicas educacionais a uma questão de democratização das relações sociais. ${ }^{29}$

Logo após, no ano de 1997, o Ministério de Educação publicou os Parâmetros Curriculares Nacionais (PCN) que traziam em seu escopo o tema de gênero e discussões transversais. Inclusive destaca-se o volume 10.5 dos temas transversais que possuía a denominação de "orientação sexual", trazendo à discussão de forma tímida a questão da sexualidade e de gênero nos currículos escolares. Segundo o próprio PCN, a abordagem da temática buscava especificamente “apontar metas de qualidade que ajudam o aluno a enfrentar o mundo atual como cidadão participativo, reflexivo e autônomo, conhecedor de seus direitos e deveres." 30 Dessa forma, o documento traz em seu escopo diversas fundamentações e auxílios teóricos com o objetivo de incluir o tema da equidade de gênero nos conteúdos curriculares.

No mesmo sentido, o Plano Nacional de Educação de 2011 a 2020 indica a necessidade da “Construção de uma nova ética (...) de modo a incluir, efetivamente, os grupos historicamente excluídos: entre outros, negros, quilombolas, pessoas com deficiências, povos indígenas, trabalhadores do campo, mulheres, lésbicas, gays, bissexuais, travestis e transexuais $\left(\mathrm{LGBT}^{31}\right)$ ". ${ }^{32}$

27 Idem, p. 40.

28 VIANNA, C. P.; UNBEHAUM, S. O gênero nas políticas públicas de educação no Brasil: 1988-2002. Caderno de Pesquisa. São Paulo, v. 34, n. 121, jan./abr. 2004. Disponível em: http: //www.scielo.br/scielo.php?script=sci_arttext\&pid $=\$ 0100-15742004000100005$. Acesso em: 15 nov. 2017.

29 MARIANO, S. A. Incorporação de gênero nas políticas públicas: incluindo os diferentes na cidadania. In: II Seminário Internacional Educação Intercultural, Gênero e Movimentos Sociais, 08 a 11 de abril de 2003, Florianópolis/SC. Disponível em:

http://titosena.faed.udesc.br/Arquivos/Artigos_gensex/Genero\%20nas\%20politicas\%20\%20publicas.pdf. Acesso em: 15 out. 2017.

30 BRASIL. Parâmetros Curriculares Nacionais: apresentação dos temas transversais: ética/Ministério da Educação. Secretaria da Educação Fundamental. 3. Ed. Brasília: A Secretaria, 2001, p.4.

31 Atualmente a sigla utilizada é LGBTI+. 
ISSN 1981-3694

(DOI): $10.5902 / 1981369431721$

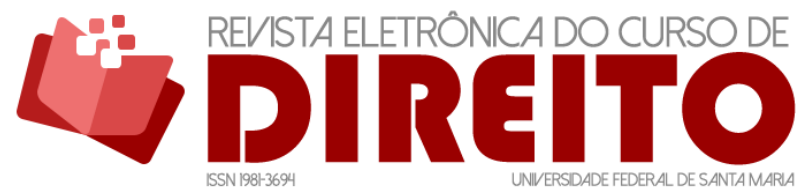

POLÍTICAS PÚBLICAS DE GÊNERO NA EDUCAÇÃO: UMA ANÁLISE PARA O DESENVOLVIMENTO

MIRIAM OLIVIA KNOPIK FERRAZ NICOLAS ADDOR JOSÉ OSÓRIO NASCIMENTO NETO

Assim, este documento amplia em muito a perspectiva de gênero e, consequentemente, a discussão sobre a equidade nas Políticas Públicas educacionais. Com essa ampliação, ele permite a consolidação de uma "política direcionada a um projeto político-pedagógico participativo" 33 e que possua como fundamento a "a autonomia, a qualidade social, a gestão democrática e participativa e a diversidade cultural, étnico-racial, de gênero, do campo", ${ }^{34}$ trazendo uma análise muito mais crítica para as salas de aula.

Denota-se então a discussão de gênero, sexualidade e outras temáticas correlatas a equidade dentro do subtema transversal intitulado "orientação sexual”. Segundo o próprio PCN, este eixo temático permite o diálogo entre professores e familiares sobre diversos temas de gênero, sexualidade ${ }^{35}$ e também do "corpo humano, relações de gênero e Prevenção às doenças sexualmente transmissíveis/AIDS". ${ }^{36}$ Destaca-se que de forma muito mais ampliativa o PCN proporciona a possibilidade da discussão sob a inspiração do feminismo pós-estruturalista, quando "propicia o questionamento de papéis rigidamente estabelecidos a homens e mulheres na sociedade, a valorização de cada um e a flexibilização desses papéis". ${ }^{37}$

Além dessas iniciativas especificamente voltadas ao âmbito da educação, tal perspectiva de diálogo entre o tripé escola-família-professores sobre os temas de gênero, sexualidade e equidade em geral foi também objeto em 2004 do Brasil sem homofobia. ${ }^{38}$

Dessa forma, observa-se que já há o incentivo para a formação de professores para as temáticas aqui elencadas, principalmente atrelado ao envolvimento dos familiares. Estas práticas possibilitam que haja uma formação pedagógica voltada à "valorização à diversidade,

32 BRASIL. Ministério da Educação. Plano Nacional de Educação de $2011-2020$, s/d, p. 56 Disponível em: http://portal.mec.gov.br/index.php?option=com_content\&id=16478\&ltemid=1107. Acesso em: $1 \mathrm{dez}$. 2017.

33 SOUSA, L. A. B.; GRAUPE, M. E. Gênero e Políticas Públicas de Educação. In: Anais do III Simpósio Gênero e Políticas Públicas, ISSN 2177-8248, Universidade Estadual de Londrina, 27 a 29 de maio de 2014. Disponível em:

http://www.uel.br/eventos/gpp/pages/arquivos/GT6_L\%C3\%Bacia\%20Aulete\%20B\%C3\%Barigo\%20de\%20 Sousa.pdf. Acesso em: 15 nov. 2017.

34 Idem.

35 BRASIL. Parâmetros Curriculares Nacionais: apresentação dos temas transversais: ética/Ministério da Educação. Secretaria da Educação Fundamental. 3. Ed. Brasília: A Secretaria, 2001, p.4.

36 Idem, p.31-34.

37 Idem.

38 BRASIL. Ministério da Saúde/Conselho Nacional do Combate à Discriminação. Brasil sem homofobia, 2014. Disponível em:

http://bvsms.saude.gov.br/bvs/publicacoes/brasil_sem_homofobia.pdf. Acesso em: 18 nov. 2017.

Revista Eletrônica do Curso de Direito da UFSM www.ufsm.br/revistadireito v. 14, n. 3 / 2019 e31721 
ISSN 1981-3694

(DOI): $10.5902 / 1981369431721$

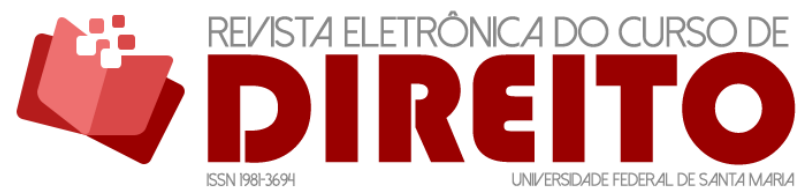

POLÍTICAS PÚBLICAS DE GÊNERO NA EDUCAÇÃO: UMA ANÁLISE PARA O DESENVOLVIMENTO

MIRIAM OLIVIA KNOPIK FERRAZ NICOLAS ADDOR JOSÉ OSÓRIO NASCIMENTO NETO

compromisso com o olhar à superação e correção de toda forma de discriminação de pessoas que desafiam a moralidade hegemônica em seus modos de ser e viver". ${ }^{39}$

Destaca-se ainda o curso "Gênero, Diversidade e Educação (GDE)" que tem como objetivo a formação e o compartilhamento de informações a respeito dos temas de gênero, orientação sexual e relações étnico-raciais, entre professores da educação básica da rede pública de ensino. ${ }^{40}$

Ressalta-se ainda que esse curso tem como parcerias quatro secretarias voltadas a Políticas Públicas em movimentos sociais: Secretaria Especial de Políticas para Mulheres (SPM), Secretaria de Políticas de Promoção da Igualdade Racial (SEPPIR), Secretaria da Educação Continuada, Alfabetização e Diversidade (SECADI), e também o Centro Latino-Americano em Sexualidade e Direitos Humanos. ${ }^{41}$

As iniciativas demonstradas nesse trabalho apresentam-se cada vez mais importantes para a consolidação de uma sociedade justa e igualitária, principalmente diante dos debates e afirmações a respeito da "ideologia de gênero", que serão tratados posteriormente neste estudo.

Destaca-se também que tais enfrentamentos e discussões devem ser objeto para o encorajamento desse importante passo, para que seja possível construir uma escola e, efetivamente, um país aberto a todos(as). ${ }^{42}$ Tal passo se inicia através dessa vertente formativa sobre gênero e diversidade dos professores e dos que trabalham com crianças e jovens, sendo este "o caminho mais consistente e promissor para um mundo sem intolerância, mais plural e democrático". ${ }^{43}$

\subsection{Políticas públicas de gênero na educação: patamar atual}

Há uma relação necessária entre o estudo de gênero e a educação, como ressalta Dagmar Estermann Meyer, ao afirmar que o processo educativo é formador dos sujeitos como "homens

39 SOUSA, L. A. B.; GRAUPE, M. E. Op.cit.

40 BRASIL. Secretaria de Governo da Presidência da República. Curso de Gênero, Diversidade e Educação (GDE), s/d. Disponível em: https://www.mdh.gov.br/sobre/a-secretaria/subsecretaria-dearticulacao-institucional-e-acoes-tematicas/coordenacao-geral-de-programas-e-acoes-de-

educacao/genero-e-diversidade-na-escola/curso-genero-e-diversidade-na-escola-gde. Acesso em: 17 out. 2017.

41 Idem.

42 FREIRE, N.; HADDAD, F.; RIBEIRO, M. Construindo uma política de educação em gênero e diversidade. In: BARRETO, A.; ARAÚJO, L; PEREIRA, M. E. (Org.) Gênero e diversidade na escola: formação de professoras/ES em gênero, orientação sexual e relações étnico-raciais. Livro de Conteúdo. Rio de Janeiro: CEPESC; Brasília: SPM, 2009.

43 Idem.

Revista Eletrônica do Curso de Direito da UFSM www.ufsm.br/revistadireito v. 14, n. 3 / 2019 e31721 
ISSN 1981-3694

(DOI): $10.5902 / 1981369431721$

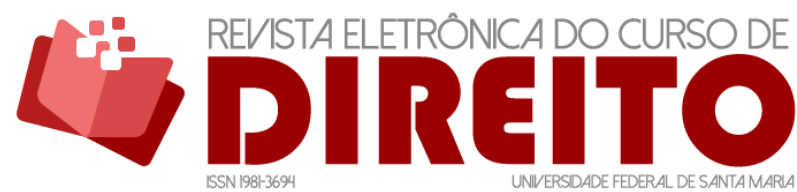

POLÍTICAS PÚBLICAS DE GÊNERO NA EDUCAC̄̃̃: UMA ANÁLISE PARA O DESENVOLVIMENTO

MIRIAM OLIVIA KNOPIK FERRAZ NICOLAS ADDOR JOSÉ OSÓRIO NASCIMENTO NETO

ou mulheres" e, também, identifica os grupos normais (heterossexuais) e os fora desse padrão, que representariam uma transgressão, uma “diferença”. ${ }^{44}$ Dessa forma, Políticas Públicas educacionais de estudo de gênero, trabalhariam esses entendimentos e auxiliariam no combate a preconceitos e discriminações.

De acordo com o Ministério da Educação e, com base no Plano Mais Brasil, a Secretaria de Educação Continuada, Alfabetização, Diversidade e Inclusão - SECADI implementa Políticas Públicas em todos os níveis de ensino destinadas ao enfrentamento de desigualdades educacionais, especialmente sobre a educação inclusiva, gênero e diversidade sexual. As políticas são destinadas à formação de educadores, distribuição de materiais didáticos, melhoria da infraestrutura das escolas e à disponibilização de recursos tecnológicos. ${ }^{45}$

Dentre as Políticas Públicas do Governo Federal destinadas ao fomento do estudo de gênero, havia o "Prêmio Construindo a Igualdade de Gênero". Tratava-se de uma premiação anual de projetos, ações, textos de estudantes do ensino médio e artigos científicos na área das relações de gênero, mulheres e feminismos para estimular e fortalecer a reflexão sobre as desigualdades existentes. ${ }^{46}$ A política, no entanto, não teve mais nenhuma edição depois da $10^{a}$, de 2015. Ainda, os vencedores da última edição passaram por dificuldades para receber os prêmios. $^{47}$

Outro programa, voltado à integração e ampliação dos serviços públicos existentes voltados às mulheres é o "Programa Mulher, Viver sem Violência" que consistiu na implementação da Casa da Mulher Brasileira, na ampliação da Central de Atendimento à Mulher, na organização e humanização do atendimento às vítimas de violência sexual, na implementação e manutenção dos Centros de Atendimento às Mulheres nas regiões de fronteira seca, nas campanhas continuadas de conscientização e na criação de unidades móveis para atendimento a mulheres em situação de violência no campo e na floresta. ${ }^{48}$

Houve também o Programa Federal de 2016, também ligado à Secretaria Nacional de Políticas para as Mulheres, com a alcunha de "Políticas para as Mulheres: Promoção da

44 MEYER, D. E. Op. cit. p. 18.

45 BRASIL, Ministério da Educação. Programas e Ações, 2017. Disponível em: http://portal.mec.gov.br/secretaria-de-educacao-continuada-alfabetizacao-diversidade-einclusao/programas-e-acoes. Acesso em: 23 nov. 2017.

46 Para mais informações, c.f.: http://www.igualdadedegenero.cnpq.br/igualdade.html.

47 Mariz, Renata. Governo Federal dá calote em vencedores de concurso de redação. 0 Globo. Disponível em:https://oglobo.globo.com/sociedade/educacao/governo-federal-da-calote-em-vencedores-deconcurso-de-redacao-21136166. Acesso em: 14 jan. 2018.

48 BRASIL. Secretaria Nacional de Políticas Públicas para as Mulheres. Programa Mulher, viver sem violência. Disponível em: https://www.mdh.gov.br/assuntos/violencia/programa-mulher-viver-semviolencia. Acesso em: 15 jan. 2018. 
ISSN 1981-3694

(DOI): $10.5902 / 1981369431721$

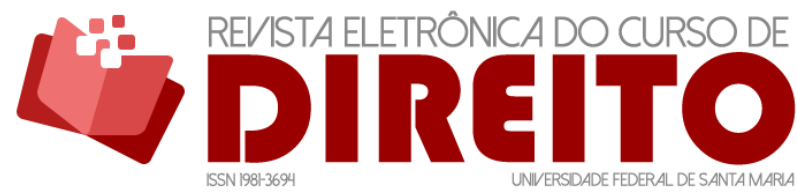

POLÍTICAS PÚBLICAS DE GÊNERO NA EDUCAÇÃO: UMA ANÁLISE PARA O DESENVOLVIMENTO

MIRIAM OLIVIA KNOPIK FERRAZ NICOLAS ADDOR JOSÉ OSÓRIO NASCIMENTO NETO

Autonomia e Enfrentamento à Violência". ${ }^{49}$ Dentre as iniciativas do programa, abarcam-se a realização de seminários e oficinas sobre a Política Nacional de Atenção Integral à Saúde da Mulher, campanha de conscientização da população sobre o Dia Internacional da Mulher, a capacitação de mulheres para o mercado de trabalho, a realização de reuniões do Fórum de Instâncias de Mulheres dos Partidos Políticos, transformar o Ligue 180 em disque denúncia e a ampliação do número de mecanismos de gênero nos órgãos do Governo Federal. ${ }^{50}$

No Ministério de Direitos Humanos, desde 31 de agosto de 2001 há a atuação do Conselho Nacional de Combate à Discriminação e Promoção dos Direitos de Lésbicas, Gays, Bissexuais, Travestis e Transexuais - CNCD/LGBT, que possui a finalidade de propor políticas governamentais em nível federal voltadas ao combate à discriminação e à defesa de direitos LGBT. ${ }^{51}$ De acordo com o sítio do Ministério dos Direitos Humanos, entretanto, atualmente há somente uma política voltada a esse grupo, intitulada "Pacto Nacional de Enfrentamento à Violência LGBTFóbica". 0 programa está dividido em cinco eixos: prevenção, investigação e responsabilização, reparação, promoção, participação e transparência. O Pacto, aparentemente, não realizou nenhuma ação efetivamente, se abstendo a informar que está a realizar reuniões nas secretarias estaduais ligadas à defesa de direitos humanos onde a gestão da política LGBT está inserida. ${ }^{52}$

Infelizmente, o que se denota é que, após 2015, coincidentemente no mesmo período do início da abertura do impeachment da então Presidenta da República Dilma Rousseff, o número de ações e de beneficiados com as políticas de estudo de gênero caiu drasticamente, com projetos sendo cancelados, secretarias do Governo próprias para a formulação de políticas para mulheres e LGBT perdendo grande parte de sua autonomia e a perda de transparência na divulgação de informações concernentes aos feitos, visto que grande parte do que é disponibilizado não é atualizado há três anos ou mais.

Apesar da péssima situação no contexto nacional, medidas no âmbito internacional vêm paulatinamente sendo implementadas no Brasil, com destaque aos programas da Organização

49 Para informações sobre o inteiro teor do Programa e suas iniciativas, c.f:

https://www.mdh.gov.br/sobre/acoes-e-programas/programas-e-objetivos-2016.pdf .

50 BRASIL. Secretaria Nacional de Políticas Públicas para as Mulheres. Resultado do Cumprimento de Metas Institucionais, 2017. Disponível em: https://www.mdh.gov.br/sobre/acoes-e-programas/1o-2o-e3o-ciclos-avaliativos-das-metas-avaliativas-2017. Acesso em: 16 jan. 2018.

51 BRASIL. Ministério dos Direitos Humanos. Conselho Nacional de Combate à Discriminação de LGBT, s.d. Disponível em: https://www.mdh.gov.br/sobre/participacao-social/cncd-lgbt. Acesso em: 16 jan. 2018.

52 BRASIL. Ministério dos Direitos Humanos. Pacto nacional de enfrentamento à violência LGBTFóbica. Disponível em: https://www.mdh.gov.br/assuntos/lgbt/programas/pacto-nacional-de-enfretamento-aviolencia-lgbtfobica. Acesso em: 16 jan. 2018. 
ISSN 1981-3694

(DOI): $10.5902 / 1981369431721$

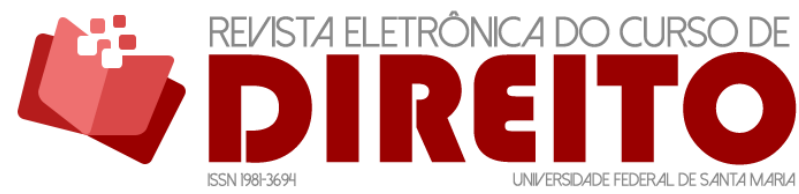

POLÍTICAS PÚBLICAS DE GÊNERO NA EDUCAÇÃO: UMA ANÁLISE PARA O DESENVOLVIMENTO

MIRIAM OLIVIA KNOPIK FERRAZ NICOLAS ADDOR JOSÉ OSÓRIO NASCIMENTO NETO

das Nações Unidas, por meio da Entidade para a Igualdade de Gênero e o Empoderamento das Mulheres, como a iniciativa "O Valente não é Violento".

Um dos projetos destinado à "Escolas - Ensino Médio: Inventário, Currículo e Planos de Aula", oferta de forma pública diversos documentos com conteúdo pedagógico livre, principalmente planos de aula completos que poderão guiar os professores na educação de gênero e ao combate a estereótipos e comportamentos de cunho machista. As aulas abordariam temas como sexo, gênero e poder; violências e suas interfaces; estereótipos de gênero e esportes; estereótipos de gênero, raça/etnia e mídia; e estereótipos de gênero, carreiras e profissões. 0 programa considerou as diretrizes do Plano Nacional de Políticas para as Mulheres $(2013-2015) .^{53}$

Já nas universidades, o projeto voltou-se ao combate à violência e preconceito existente nos trotes universitários contra os(as) ingressantes nos cursos de graduação, com a divulgação de uma "Carta pelo Fim do Trote Violento contra Gênero e Raça", com propostas como a "elaboração de uma campanha de mídia e advocacy contra o trote violento, que conscientize universitárias e universitários a respeito da violência de gênero e de raça, e a formação de uma rede institucionalizada de apoio, com a implementação de comitês de apuração e ouvidorias". ${ }^{54}$

\subsection{Críticas às políticas públicas de inclusão ao estudo de gênero na educação}

Atualmente tem-se observado em diversos países o surgimento e o fortalecimento de grupos mobilizados a acabar com a "ideologia de gênero" e os seus "outros nomes", como "gênero", "teoria de gênero" etc. O principal objetivo desses movimentos e adeptos é "conclamar a sociedade para enfrentar um inimigo". ${ }^{55}$ Essa luta deixou de estar restrita ao campo de meras opiniões e passou a fundamentar propostas e ações políticas.

O principal argumento utilizado para estes grupos serem contrários à tida “ideologia de gênero" está na busca da restauração da ordem sexual tradicional e o reforço às normas de gênero, sendo esta obrigatoriamente vinculada à heterossexualidade e à heteronormatividade. ${ }^{56}$

53 ORGANIZAÇÃO DAS NAÇÕES UNIDAS. Gênero na escola e na universidade, 2016. Disponível em: http://www.onumulheres.org.br/programasemdestaque/genero-na-escola/. Acesso em: 30 jan. 2018. 54 Idem.

55 JUNQUEIRA, R. D. "Ideologia de Gênero": a invenção de uma categoria polêmica contra os direitos sexuais. In: RAMOS, M. M.; NICOLI, P. A. G.; ALKMIN, G. C. (Orgs.). Gênero, sexualidade e direitos humanos. Perspectivas multidisciplinares. Belo Horizonte: Initia Via, 2017, p. 221.

56 Op. Cit., p. 221. 
ISSN 1981-3694

(DOI): 10.5902/1981369431721

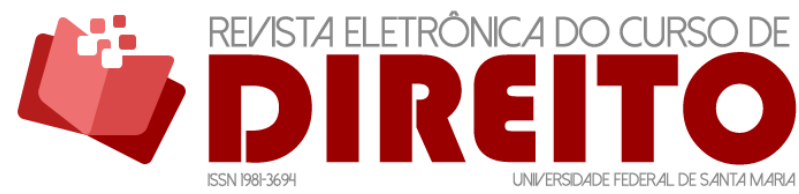

POLÍTICAS PÚBLICAS DE GÊNERO NA EDUCAÇÃO: UMA ANÁLISE PARA O DESENVOLVIMENTO

MIRIAM OLIVIA KNOPIK FERRAZ NICOLAS ADDOR JOSÉ OSÓRIO NASCIMENTO NETO

A terminologia “ideologia de gênero" e suas respectivas variações, tem origem apontada por muitos estudiosos entre os desígnios do Conselho Pontifício para a família e conferências episcopais que ocorreram entre 1990 e os anos $2000 . .^{57}$

Destaca-se o livro realizado pelo monsenhor ${ }^{58}$ Michel Schooyans, intitulado " $L$ 'Évangile face au désordre mondial" em 1997, o qual possui grande espaço para a denúncia da "ideologia de gênero", sendo esta uma das primeiras obras em que o termo foi citado. ${ }^{59}$ No ano seguinte, esta terminologia foi primeiramente posta em um documento eclesiástico, a nota da Conferência Episcopal do Peru, intitulada “La ideologia de género: sus peligros y alcances” produzida pelo monsenhor Oscar Alzamora Revoredo, bispo auxiliar de Lima. Nesta, afirmou que a palavra "gênero" escondia a intenção de "toda uma ideologia" que pretenderia modificar o pensamento humano sobre a estrutura bipolar. Complementando que "a moral fica à livre decisão do indivíduo e desaparece a diferença entre o permitido e o proibido nessa matéria”. ${ }^{60}$ Logo após, em 2000, a terminologia foi novamente utilizada e, pela primeira vez, em um documento da Cúria Romana pelo Conselho Pontifício para a Família, no qual destacam-se trechos sobre a difusão da ideologia de gênero se tratar de um processo de "gradual desestruturação cultural e humana da instituição matrimonial". ${ }^{61}$

Mas desenvolveu-se paralelamente também em outras áreas, como a própria associação “National Association for Research \& Terapy of Homossexuality", fundada em 1992, que promove estudos e práticas de terapias que objetivam a reparação da homossexualidade. ${ }^{62}$

Avançando para os pronunciamentos dos anos 2000, em 2008 o Papa Bento XVI no “Discurso à Cúria Romana por Ocasião dos Votos de Feliz Natal” descreveu "gender" como algo

57 CANARC, Romain. L'Église catholique contre "la théorie du genre": construction d'un objet polémique dans le débat public français contemporains. Synergies Italie, $\mathrm{n}^{\circ} .10,2014, \mathrm{p} .125-143$; GARBAGNOLI, Sara. "L'ideologia del genere": l'irresistible ascesa di um"invenzione retorica vaticana contro la denaturalizzazione dell"ordine sessuale. AG About Gender, v.3, n.6, 2014, p.250-263; HUSSON, AnneCharlotte. Stop à la rumeur:parlons de genre: GenERe- Genre. Lyon, 2014; PATERNOTTE, David. “Habemus gender" Autopsie d'une obsession vaticane. In: PIETTE, V.;,PATERNOTTE, D.; DUSSEN, S. van der (Dir.). Habemus gender! Autopsie d'une obsession vaticane. Brucelas: EUB, 2016, p.7-22; ROSADONUNES, M. J. F. A "ideologia de gênero" na discussão do PNE: a intervenção da hierarquia católica. Horizonte, Belo Horizonte, v.13, n. 39, jul/dez 2015, p.1237-1260

58 Monsenhor é um dos títulos da igreja católica, que é um título é honorífico de alto nível, onde não é necessário fazer nenhum tipo de curso específico. A BíBLIA, Uma Janela sobre o mundo bíblico, s.d. Disponível em: http://www.abiblia.org/ver.php?id=4210. Acesso em: 18 nov. 2017

59 JUNQUEIRA, Rogério Diniz. Op. Cit., p.226.

60 ALZAMORA REVOREDO, O. La ideologia de género: sus peligros y alcances. Lima: Conferencia Episcopal Peruana, 1998.

61 PONTIFÍCIO CONSELHO PARA A FAMÍLIA. Família, matrimônio e "uniões de fato". Cidade do Vaticano, 2000.

62 NARTH INSTITUTE, The Alliance (ATCSI) - NARTH Institute Statement on Sexual Orientation Change, s.d. Disponível em: https://www.narth.com/about1.Acesso em: 15 nov. 2017. 
ISSN 1981-3694

(DOI): $10.5902 / 1981369431721$

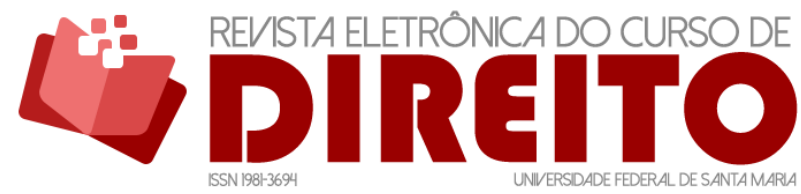

POLÍTICAS PÚBLICAS DE GÊNERO NA EDUCAC̄̃̃: UMA ANÁLISE PARA O DESENVOLVIMENTO

MIRIAM OLIVIA KNOPIK FERRAZ NICOLAS ADDOR JOSÉ OSÓRIO NASCIMENTO NETO

que "contrariaria e desprezaria a natureza e poderia levá-lo (o homem) a autodestruição". ${ }^{63}$ Posicionamento que se manteve em 2012 pelo referido papa que, além disso, condenou expressamente o tema. ${ }^{64}$

Outro argumento levantado por posições contrárias ao estudo de gênero seria a inconstitucionalidade da inclusão do debate nas escolas públicas e privadas, por atentar contra a autonomia familiar de condução da educação moral e sexual de seus filhos. Como bem salientado por Ilmar Pereira do Amaral Júnior, o argumento é logo repelido por duas razões: a) ele desconsidera que as identidades também são formadas no espaço público, tanto espontaneamente mas também por atribuição de lugares sociais pela cultura dominante, e; b) por se basear numa falsa compreensão de privacidade, conferindo direitos à família de prejudicar a autonomia dos indivíduos. ${ }^{65}$

A tendência dos movimentos que buscam o "direito a uma escola não-ideológica" ou uma “'escola sem gênero"66 é o enfrentamento de uma diversidade de propostas educacionais. Diversas pautas e propostas que buscam escolas inclusivas, não discriminatórias, que valorizam a laicidade, o pluralismo e, principalmente, o reconhecimento da diferença são tidos como "ameaças à liberdade de expressão, crença e consciência". ${ }^{67}$ Inclusive crescem os discursos de incompatibilidade dos "valores morais da família" ${ }^{68}$ com as normativas nacionais e internacionais de direitos humanos. ${ }^{69}$

Simultaneamente aos debates contra a "ideologia de gênero" levantados em instituições acadêmicas, congressos e associações, o contra movimento vislumbrou nas redes sociais uma maneira de divulgação global de seus posicionamentos. No Brasil, esse levante seguiu em

63 BENTO XVI, Discurso à Cúria Romana na Apresentação de Votos de Feliz Natal. Cidade do Vaticano, 22 de dezembro de 2008 In: JUNQUEIRA, R. D. Op. Cit., p.231.

64 Idem.

65 AMARAL JÚNIOR, I. P. Op. Cit, p.111.

66 JUNQUEIRA, R. D. Op. Cit., p. 233.

67 Idem.

68 Valores sociais da família que são abordados por Antônio Henrique Maia Lima como "concepção binarista", responsável por um "discurso autoritário, moralista e religioso de culpabilização, que simultaneamente: a) condena a existência de característica diferente; b) atribui ao indivíduo diferente a responsabilidade por ser diferente; c) promove a reprovação do diferente pela totalidade do grupo dominante, mais homogêneo; d) obriga direta ou indiretamente o indivíduo diferente a abrir mão de sua diferença (se possível) para assegurar a manutenção da identidade e do pertencimento ao grupo dominante; e) sugere ao grupo dominante punições ao indivíduo diferente que se negue a ou (sic) não possa abrir mão de sua diferença e; f) promove a exclusão do indivíduo diferente do grupo dominante". LIMA, A. H. M. O direito humano ao desenvolvimento sob a ótica das minorias de gênero. Dissertação (Mestrado em Desenvolvimento Local) - Universidade Católica Dom Bosco, 2015, p. 82.

69 JUNQUEIRA, R. D. Op. Cit., p.233. 
ISSN 1981-3694

(DOI): $10.5902 / 1981369431721$

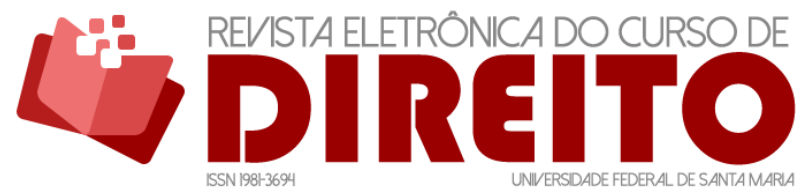

POLÍTICAS PÚBLICAS DE GÊNERO NA EDUCAC̄̃̃: UMA ANÁLISE PARA O DESENVOLVIMENTO

MIRIAM OLIVIA KNOPIK FERRAZ NICOLAS ADDOR JOSÉ OSÓRIO NASCIMENTO NETO

conjunto com a expansão de igrejas $^{70}$ e a ocupação de seus líderes nos cargos eletivos das diversas esferas do Governo, além da ascensão de movimentos em defesa da família tradicional (cristã, paternalista e heteronormativa).

0 que se analisa hoje é que o contra movimento no Brasil $^{71}$ passou de discussões acadêmicas para debates acirrados, sem fundamentos e, muitas vezes, preconceituosos nas redes sociais. Surgiram congregações das mais diversas naturezas, com o amplo poderio da internet, utilizada para garantir que suas opiniões (fundamentadas ou não) possam ser consideradas como verdade pela ampla maioria que os assistem. Até a propagação de mentiras é utilizada como arma para calar um movimento que busca a igualdade e liberdade de gênero.

A amplitude e propagação do debate fora dos centros de poder já foi previsto em 1997 por Anthony Giddens, Ulrich Beck e Scott Lash. O processo de mutação da sociedade moderna (industrial) para uma modernização reflexiva, em razão de seu dinamismo, está por acabar com as formações de classe, camadas sociais, ocupações, papéis dos sexos, família e economia, num processo de autodestruição criativa. ${ }^{72}$ A esfera política não é desconsiderada nessa transição: se, por um lado, se está desenvolvendo um vazio político das instituições antes consideradas centros polarizados de poder, por outro, há o renascimento não institucional do político. ${ }^{73}$ Por isso, o que se observa é que hoje a discussão avançou para a sociedade, para todos os nichos de comunidades, dando voz para classes outrora oprimidas, mas também elevando posicionamentos preconceituosos.

Dessa forma, é importante destacar que a referida "ideologia de gênero" não corresponde efetivamente a agenda de debates dos Estudos de Gênero, movimentos feministas ou LGBTI+, mas é um conceito criado para ser refutado e que em nada absorve as discussões reais sobre a temática. É importante ressaltar a diferença entre propor práticas e estudos de equidade de gênero, de aproximação com as minorias (nas mais diversas materializações), de um debate de uma teoria social específica de gênero fluído ou queer. ${ }^{74}$

70 Importante ressaltar que atualmente a própria igreja católica possui como uma de suas vertentes a "Pastoral da Diversidade" que busca trazer o próprio ensino e vivência da religião de forma inclusiva.

71 Exemplos de países em que têm ocorrido campanhas conta a "ideologia de gênero": França, Itália, Espanha, Portugal, Alemanha, Bélgica, Polônia, Croácia, Eslovênia, Eslováquia, Lituânia, Finlândia, Estados Unidos, Canadá, Argentina, Uruguai, Chile, Bolívia, Peru, Equador, Colômbia, Panamá, Costa Rica, Guatemala, México, Porto Rico, República Dominicana, Austrália, Nova Zelândia, Taiwan, entre outros. JUNQUEIRA, R. D. Idem, p.232.

72 GIDDENS, A.; BECK, U.; LASH, S. Modernização Reflexiva. São Paulo: UNESP, 1997, p.12.

73 Idem, p.28.

74 Gênero fluído (genderfluid) pode ser entendido como a não identificação com um sexo fixo (homem ou mulher), podendo isso variar de acordo com a sensibilidade individual, com o contexto, momento, história, perspectivas e etc. OXFORD DICTIONARIES, Genderfluid. Disponível em: 
ISSN 1981-3694

(DOI): $10.5902 / 1981369431721$

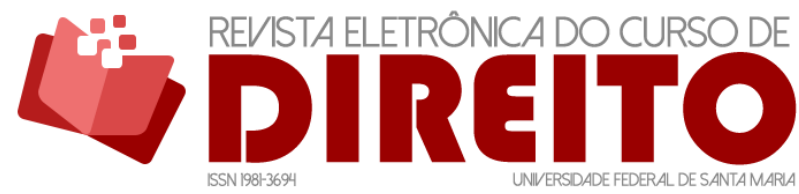

POLÍTICAS PÚBLICAS DE GÊNERO NA EDUCAÇÃO: UMA ANÁLISE PARA O DESENVOLVIMENTO

MIRIAM OLIVIA KNOPIK FERRAZ NICOLAS ADDOR JOSÉ OSÓRIO NASCIMENTO NETO

Após analisar as críticas infundadas contra o estudo de gênero, é necessário analisar, em primeiro lugar, o seu objeto de estudo, utilizando das palavras de Georgiane Garabely Heil Vázquez, que sustenta que o movimento não possui como objetivo modificar a sexualidade do indivíduo, ou mesmo defender a erotização infantil. Ela significa o oposto, ao estabelecer um estudo sobre a realidade social existente, inclinando-se principalmente à pesquisa sobre a organização de papeis sociais numa imagem socialmente construída, procurando compreender a ideia da hegemonia da masculinidade, a influência nas opções sociais de homens, mulheres e crianças, além de propor novos modelos sociais. ${ }^{75}$ Reforçando que, como bem ressalta Antônio Henrique Maia Lima, a manifestação da hegemonia da visão binária da sexualidade humana se dá pelo discurso (intelectual e moral). ${ }^{76}$

Assim sendo, o que se constata é que no momento em que presenciamos o desrespeito generalizado como no recente caso da Organização das Nações Unidas fomentar uma cultura de silêncio quanto à denúncia de abusos sexuais ${ }^{77}$ ou as recentes denúncias de assédio em desfavor de diversos atores consagrados em Hollywood, ${ }^{78}$ a discussão sobre educação familiar, social e escolar atualmente em vigor vem à tona com o propósito de ser questionada. Afinal, o comportamento social de hoje foi o aprendizado de ontem.

\section{A INCLUSÃO DO ESTUDO DE GÊNERO NA EDUCAÇÃO COMO CAMINHO PARA O DESENVOLVIMENTO}

Superados os debates e posições contrários à implementação do estudo de gênero, a reflexão deste presente estudo impele para que se dobre à sua projeção para a sociedade.

https://www.lexico.com/en/definition/gender-fluid. Acesso em: 10 dez. 2017. BARRETO, E. S.; LIRA, Igor. Sociedade do trabalho e a vida determinada pela Identidade de gênero: por uma perspectiva materialista da condição socioeconômica da comunidade trans. Revista Trabalho Necessário. ano 15, n. 28, 2017. A teoria queer, afirma que a orientação sexual e a identidade sexual ou de gênero dos indivíduos são o resultado de um constructo social e que, portanto, não existem papéis sexuais essencial ou biologicamente inscritos na natureza humana. Seria algo construído externamente ao indivíduo e estaria relacionada a uma imposição de necessidade de adaptação do indivíduo à sociedade. BUTLER, J. Op. cit., p. 122.

75 VÁZQUEZ, G. G. H. Gênero não é ideologia: explicando os Estudos de Gênero, 2017. Disponível em: https://www.cafehistoria.com.br/explicando-estudos-de-genero. Acesso em: 15 jan. 2018.

76 LIMA, A. H. M. Op. Cit. p. 71.

77 ÉPOCA. ONU é acusada de permitir abusos sexuais em seus escritórios, 2018. Disponível em: https://epocanegocios.globo.com/Mundo/noticia/2018/01/onu-e-acusada-de-permitir-abusos-sexuais-emseus-escritorios.html. Acesso em: 19 jan. 2018.

78 ISTOÉ. Hollywood e o assédio sexual: cresce a lista de acusados, 2017. Disponível em: https://istoe.com.br/hollywood-e-o-assedio-sexual-cresce-a-lista-de-acusados/. Acesso em: 19 jan. 2018. 
ISSN 1981-3694

(DOI): $10.5902 / 1981369431721$

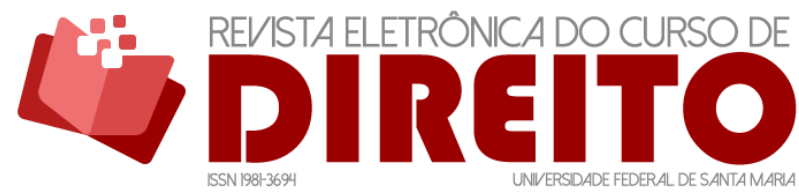

POLÍTICAS PÚBLICAS DE GÊNERO NA EDUCAÇÃO: UMA ANÁLISE PARA O DESENVOLVIMENTO

MIRIAM OLIVIA KNOPIK FERRAZ NICOLAS ADDOR José OSÓRIO NASCIMENTO NETO

Considera-se, pois, o conhecimento e a informação como alicerces para uma visão mais ampla dos valores. Como base para a cidadania em sociedades plurais, cambiantes e complexas, a educação passou então a ocupar de forma definitiva um lugar central na pauta das macropolíticas do Poder Público, por constituir-se em um meio importante na tentativa de assegurar a justiça social, buscando o fim de discriminações sociais, a erradicação da violência e o fortalecimento de outros comportamentos mais solidários. ${ }^{79}$

Guiomar Namo de Mello defende a descentralização escolar, o que possibilitaria a cada instituição ter certa liberdade para construir uma identidade institucional própria, e estar capacitada a definir uma proposta pedagógica com objetivos concretos. Essas instituições, conforme o autor, são as que produzem melhores resultados. A mera capacitação de professores, mudanças curriculares e fornecimento de material de ensino não é aproveitada se não há uma interação entre eles por causa da dinâmica do funcionamento escolar. ${ }^{80}$ Apesar do caráter federativo da república brasileira, as Políticas Públicas da União e a leitura feita pelos governos estaduais e municipais são ainda propostas muito centralizadas na elaboração, e é premente a necessidade de envolver todos os responsáveis pela educação. ${ }^{81}$

0 que se necessita, dessa maneira, não é somente uma maior articulação dos interessados para a tomada de decisões, mas também uma mudança estrutural na escola como instituição, tanto na estrutura física em si, que possibilite um ambiente acolhedor de conhecimento e aprendizado, quanto na qualificação dos educadores e demais servidores no que concerne à formação docente voltada à reflexão de conceitos e ao trabalho com a diversidade para o combate à desigualdade. ${ }^{82}$

Neste momento analisa-se os seguintes planos nacionais: Plano Nacional de Políticas para Mulheres; O Plano Nacional de Promoção da Igualdade Racial e a Política Nacional de Promoção da Igualdade Racial; o Plano Nacional dos Direitos da Pessoa com Deficiência, e; o Plano Nacional de Educação, para verificar se é possível e se há o reconhecimento da importância do estudo de gênero nos mesmos. Posteriormente, analisa-se as propostas que podem contribuir diretamente com essa construção: o anteprojeto do Estatuto da Diversidade Sexual e de Gênero e o Currículo de Gênero, sob iniciativa da ONU Mulheres, em parceria com a iniciativa "O Valente não é violento".

\footnotetext{
79 MELLO, G. N. Políticas públicas de educação. Estud. av., São Paulo, v. 5, n.13, p. 7-47, dez.1991. 80 Idem.

81 VIANNA, C. Gênero, sexualidade e políticas públicas de educação: um diálogo com a produção acadêmica. Pro-Posições, Campinas, v. 23, n. 2, p.127-143, maio/ago. 2012.

82 VIANNA, Cláudia. Idem.
} 
ISSN 1981-3694

(DOI): $10.5902 / 1981369431721$

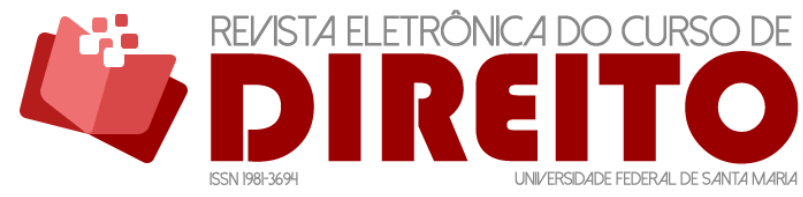

POLÍTICAS PÚBLICAS DE GÊNERO NA EDUCAÇÃO: UMA ANÁLISE PARA O DESENVOLVIMENTO

MIRIAM OLIVIA KNOPIK FERRAZ NICOLAS ADDOR JOSÉ OSÓRIO NASCIMENTO NETO

O Plano Nacional de Políticas para Mulheres III desenvolvido nos anos de 2013 a 2015, será o referencial inicial desse estudo. Em pesquisa no sítio eletrônico da Secretaria Nacional de Políticas para Mulheres (Secretaria De Governo Da Presidência Da República) não se encontrou dados ou planos mais atuais ${ }^{83}$. Portanto, estuda-se o plano realizado no feixe histórico citado.

O Plano Nacional de Políticas para Mulheres possui, dentre outros enfoques, a centralização na educação como um dos eixos basilares para a formação de uma sociedade igualitária entre mulheres e homens. Admite que, até o momento de entrega do feedback desse plano, "a educação brasileira ainda não incorporou totalmente o princípio da igualdade de gênero". ${ }^{84}$

Ressalta-se que a paridade nas matrículas foi alcançada em quase todos os níveis de ensino, mas a desigualdade permanece nos conteúdos educacionais, nos cursos e nas carreiras acessados por mulheres e homens. Vários indicadores demonstram que permanece insistentemente as desigualdades associadas à discriminação sexista, étnica e racial, à concentração de renda, à desigualdade de renda entre campo e cidade. ${ }^{85}$

O Plano ainda ressalta a importância de se analisar a questão de gênero sempre atrelada às discussões de raça, etnia, rural/urbano e orientação sexual para, somente com esse viés amplo, desenvolver políticas específicas que combatam preconceitos, inclusive entre mulheres. ${ }^{86}$

Como elencado anteriormente sobre a naturalização e a padronização de comportamentos, o próprio plano ressalta que a escola muitas vezes reproduz as desigualdades vivenciadas tanto nos currículos, como nos livros didáticos, nas práticas das salas de aula, nos procedimentos de avaliação, na linguagem sexista e na invisibilidade das mulheres na ciência e na história, ${ }^{87}$ e nas próprias práticas dos educadores. ${ }^{88}$

83 BRASIL, Presidência da República. Secretaria Nacional de Políticas para Mulheres. Plano Nacional de Políticas para as Mulheres, 2013. Disponível em: https://www.mdh.gov.br/assuntos/pnpm. Acesso em: 15 dez. 2017.

84 Idem.

85 Idem.

86 Op. Cit.

87 Idem.

88 BARCELOS, L.C. Educação e desigualdades raciais no Brasil. Cadernos de Pesquisa, n. 86, ago 1993, p. 15-24; CANDAU, V. M. F. Educação escolar e cultura(s). Tecnologia Educacional, v. 22, n. 125, jul./ago. 1995, p. 23-28; CANEN, A. Universos culturais e representações docentes: subsídios para a formação de professores para a diversidade cultural. Educação \& Sociedade, ano XXII, n. 77, dez. 2001; LÜDKE, M., MEDIANO, Z. Avaliação na escola de $1^{\circ}$ grau: uma análise sociológica. Campinas: Papirus, 1992. 
ISSN 1981-3694

(DOI): $10.5902 / 1981369431721$

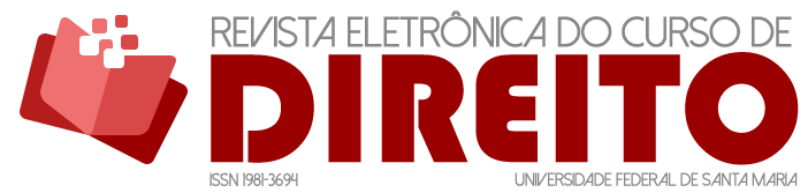

POLÍTICAS PÚBLICAS DE GÊNERO NA EDUCAÇÃO: UMA ANÁLISE PARA O DESENVOLVIMENTO

MIRIAM OLIVIA KNOPIK FERRAZ NICOLAS ADDOR JOSÉ OSÓRIO NASCIMENTO NETO

O Plano ressalta que as políticas de educação para a igualdade de gênero do Governo Federal adotam o duplo movimento: “ações que transformem as percepções e modos de vida, e ações diretas de combate à desigualdade de oportunidades". ${ }^{89}$

Ressalta-se, por fim, que as prioridades do Plano Nacional de Políticas para Mulheres já vislumbram a necessidade de uma educação verdadeiramente inclusiva, como se observa: i) Promover a formação de gestores/as e profissionais da educação para a equidade de gênero, raça/etnia e o reconhecimento das diversidades; ii) Promover a formação de estudantes da educação básica no mesmo sentido; iii) Promover a formação das mulheres jovens e adultas para o trabalho, inclusive nas áreas científicas e tecnológicas; iv) Estimular a produção e difusão de conhecimentos sobre gênero, identidade, orientação sexual e raça/etnia em todos os níveis de ensino; v) Promover medidas educacionais para o enfrentamento da violência contra as mulheres (considerando dimensões étnico-raciais, de orientação sexual e geracionais); v) Ampliar o acesso e a permanência na educação de grupos específicos de mulheres com baixa escolaridade. ${ }^{90}$

O Plano Nacional de Promoção da Igualdade Racial foi instituído pelo Decreto $\mathrm{n}^{\circ}$ 6.872/2009 e possui diretrizes e eixos específicos direcionados à educação e ao combate a discriminações, quais sejam: i) Eixo 1: Trabalho e Desenvolvimento Econômico, inciso II promover a equidade de gênero, raça e etnia nas relações de trabalho e combater as discriminações; ii) Eixo 4: Diversidade Cultural, inciso II, que evidencia a necessidade da eliminação da veiculação de estereótipos de gênero, raça, cor e etnia nos meios de comunicação; ${ }^{91}$ Destaca-se também a Política Nacional de Promoção da Igualdade Racial que entende como um dos objetivos do plano a articulação da temática de raça com gênero. Entende-se, inclusive, como aspectos da violação dos direitos humanos a discriminação combinada entre raça e gênero, "afetando diretamente as mulheres negras e demarcando um cenário de desagregação social e de redução da qualidade de vida". ${ }^{92}$

O Plano nacional dos Direitos da Pessoa com Deficiência não possui abordagens que interrelacionam a deficiência com fatores, raciais, étnicos e de gênero. ${ }^{93}$ Há apenas a disposição

89 BRASIL, Presidência da República. Secretaria Especial de Políticas para as Mulheres. II Plano Nacional de Políticas para as Mulheres. $2^{a}$ Reimpressão. Brasília: Secretaria Especial de Políticas para as Mulheres, 2008, p. 57. Disponível em: https://www.mdh.gov.br/assuntos/pnpm/livro-ii-pnpmcompleto09.09.2009.pdf Acesso em: 15 dez. 2017.

90 Idem.

91 BRASIL, Política Nacional de Promoção da Igualdade Racial. Disponível em: http://bvsms.saude.gov.br/bvs/publicacoes/politica_nacional_promocao_igualdade_racial.pdf. Acesso em: 15 dez. 2017.

92 Idem.

93 BRASIL, Plano Nacional dos direitos das pessoas com deficiência. Disponível em: 
ISSN 1981-3694

(DOI): $10.5902 / 1981369431721$

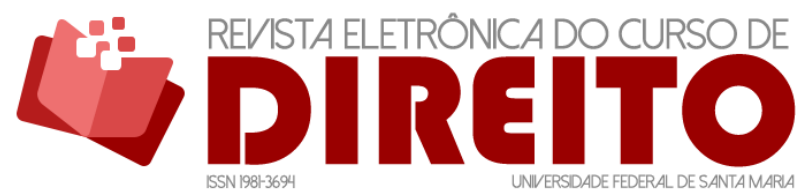

POLÍTICAS PÚBLICAS DE GÊNERO NA EDUCAÇÃO: UMA ANÁLISE PARA O DESENVOLVIMENTO

MIRIAM OLIVIA KNOPIK FERRAZ NICOLAS ADDOR JOSÉ OSÓRIO NASCIMENTO NETO

ampla de que acesso à educação é "direito de todos, sem discriminação, em igualdade de oportunidades". ${ }^{94}$ Tal entendimento é severamente criticado, como elenca o Coordenador-geral do Conade, Anderson Correia, que propõe a discussão da transversalidade das Políticas Públicas para pessoas com deficiência.

Antes, a discussão sempre foi setorial: saúde, educação, transporte e lazer. É preciso lembrar que a deficiência não é a única característica da pessoa. É um homem ou uma mulher; tem uma identidade de gênero e uma orientação sexual; faz parte de uma faixa etária; tem sua raça ou etnia. Todas essas características precisam ser pensadas juntas e de forma transversal. ${ }^{95}$

O Plano Nacional de Educação define metas, estratégias e diretrizes para a educação brasileira de 2014 a 2024, que são divididos em grupos: a) metas para a garantia do direito à educação básica com qualidade, de forma universal e a ampliação de oportunidades; b) metas para redução das desigualdades e valorização da diversidade; c) metas de valorização dos profissionais da educação; d) metas para a educação superior. ${ }^{96}$

Dessa forma, observa-se que o estudo de gênero na educação não é novidade e é imprescindível para a concretização de vários direitos de mulheres e homens; negras e negros; índias e índios; pessoas com deficiência etc., de forma transversal e completa. Este estudo está elencado especificamente no Plano Nacional de Políticas para Mulheres e na Política Nacional de Promoção da Igualdade Racial e de forma paralela no Plano Nacional de Promoção da Igualdade Racial, no Plano Nacional dos Direitos da Pessoa com Deficiência e no Plano Nacional de Educação.

Assim, o Projeto de Lei 2731/2015 que objetiva alterar o Plano Nacional de Educação (PNE) para proibir a discussão de gênero dentro das escolas é fundado em premissas e perspectivas completamente erradas. A exclusão da discussão sobre gênero (aqui entendida de forma ampla a abranger mulheres, etnias, raças, comunidade LGBTI+, desigualdade social e temas correlatos a masculinidades) é completamente incompatível com os planos nacionais que buscam o desenvolvimento social: o Plano Nacional de Políticas para Mulheres; a Política

https: / /www.mdh.gov.br/navegue-por-temas/pessoa-com-

deficiencia/app/sites/default/files/arquivos/\%5Bfield_generico_imagens-filefield-description\%5D_0.pdf. Acesso em: 15 dez. 2017.

94 Idem.

95 BRASIL, Cidadania e Justiça. Pessoas com deficiência ganham espaço na pauta dos direitos humanos, diz Conade, 2016. Disponível em: http://www.brasil.gov.br/cidadania-ejustica/2016/04/colocamos-o-debate-de-pessoas-com-deficiencia-no-campo-dos-direitos-humanos-dizpresidente-do-conade. Acesso em: 15 dez. 2017.

96 BRASIL, Ministério da Educação. Planos de Educação, . Disponível em: http://pne.mec.gov.br/planosde-educacao. Acesso em: 20 jan. 2018. 
ISSN 1981-3694

(DOI): $10.5902 / 1981369431721$

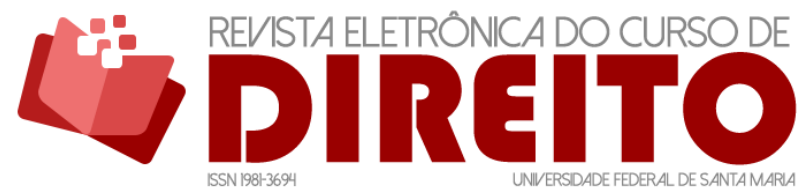

POLÍTICAS PÚBLICAS DE GÊNERO NA EDUCAÇÃO: UMA ANÁLISE PARA O DESENVOLVIMENTO

MIRIAM OLIVIA KNOPIK FERRAZ NICOLAS ADDOR José OSÓRIO NASCIMENTO NETO

Nacional de Promoção da Igualdade Racial, o Plano Nacional de Promoção da Igualdade Racial, Plano Nacional dos Direitos da Pessoa com Deficiência e o Plano Nacional de Educação.

Ainda, a implementação de um projeto de lei que visa excluir quaisquer discussões e formações em prol do combate às discriminações e desigualdades estaria completamente contra o sentido das políticas educacionais, que visam a formação e a estruturação de cidadãos e cursos voltados a emancipação dos indivíduos de forma igualitária e justa.

Por outro lado, iniciativas que fomentam a ampliação do estudo de gênero nas escolas devem ser valorizadas, como o Anteprojeto Estatuto da Diversidade Sexual e de Gênero elaborado pela Comissão Especial da Diversidade Sexual e Gênero da Ordem dos Advogados do Brasil, que propõe, dentre outras coisas, o enfoque em uma educação não discriminatória e igualitária. De forma sintetizada, destacam-se alguns institutos: Art. 56 - Os estabelecimentos de ensino (públicos e privados) têm o dever de promover a liberdade, a tolerância, a igualdade, a diversidade e o respeito entre as pessoas, independentemente de sua orientação sexual ou identidade de gênero; Art. 57 - Os professores, diretores, supervisores, psicólogos, psicopedagogos e etc. têm o dever de evitar qualquer atitude preconceituosa ou discriminatória por orientação sexual e identidade de gênero.; Art. 58 - Os profissionais da educação têm o dever de abordar os temas relativos à sexualidade, adotando materiais didáticos que não reforcem a discriminação com base na orientação sexual ou identidade de gênero; Art. 59 Gera responsabilidade civil e penal à omissão dos dirigentes e dos professores que não coibirem, no ambiente escolar, ações discriminatórias em decorrência de sua orientação sexual ou identidade de gênero; Art. 60 - Programação de atividades escolares referentes a datas comemorativas devem atentar à multiplicidade de formações familiares; Art. 61 - 0 poder público deve promover a capacitação dos professores para uma educação inclusiva e evitar a evasão escolar; Art. 62 - Assegurado o uso do nome social em todos os níveis de ensino. ${ }^{97}$

Dessa forma, se observa que em nenhum momento se concretizam as falsas notícias de "desconstrução de gênero" ou "quebra da unidade familiar" e, sim, objetiva-se a formação de um ambiente escolar inclusivo e que respeite as diferenças.

Ressalta-se, por fim, a proposta de um Currículo de Gênero, sob iniciativa da ONU Mulheres, em parceria com a iniciativa "O Valente não é violento", que promove a igualdade de gênero nas escolas sob o enfoque do combate ao machismo. A proposta é colocada como um

97 ORDEM DOS ADVOGADOS DO BRASIL. Comissão Especial da Diversidade Sexual. Anteprojeto Estatuto da Diversidade Sexual e de Gênero Disponível em: http://legis.senado.leg.br/sdleggetter/documento?dm=7302364\&disposition=inline. Acesso em: $20 \mathrm{dez} .2017$. 
ISSN 1981-3694

(DOI): $10.5902 / 1981369431721$

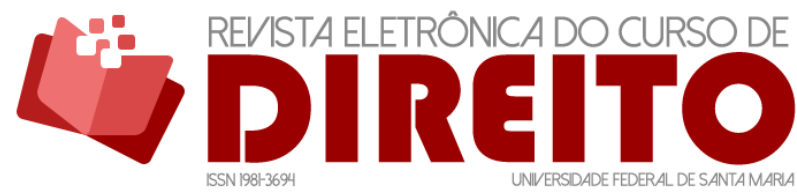

POLÍTICAS PÚBLICAS DE GÊNERO NA EDUCAÇÃO: UMA ANÁLISE PARA O DESENVOLVIMENTO

MIRIAM OLIVIA KNOPIK FERRAZ NICOLAS ADDOR JOSÉ OSÓRIO NASCIMENTO NETO

convide aos educadores para "repensar e transformar ideias pré-concebidas sobre o que é "ser homem" e o que é "ser mulher"”. ${ }^{98}$

A iniciativa disponibiliza um Currículo de Gênero e seis Planos de aula completos e prontos para serem aplicados, sobre os temas: i) sexo, gênero e poder; ii) violências e suas interfaces; iii) estereótipos de gênero e esportes; iv) estereótipos de gênero, raça/etnia e mídia; v) estereótipos de gênero, carreiras e profissões: diferenças e desigualdades; vi) vulnerabilidades e prevenção. ${ }^{99}$

A proposição é tão ampla e planejada que está vinculada a três eixos: i. Linguagens, Códigos e suas tecnologias; ii. Ciências da Natureza e suas tecnologias; iii) Ciências Humanas e suas tecnologias e iv) Matemática e suas tecnologias. Em cada área específica há a abordagem das seguintes temáticas: discussão das normas sociais de gênero, questionando a reprodução das desigualdades entre homens e mulheres, muitas vezes naturalizadas e banalizadas no cotidiano; direitos sexuais e reprodutivos, fomentando a promoção de uma visão positiva acerca da sexualidade, adotando a perspectiva de gênero e de direitos, incluindo temáticas acerca da saúde; violências baseadas em gênero, com o objetivo de questionar assimetrias de poder nas relações.

As iniciativas apresentadas estão completamente alinhadas com os propósitos das recomendações referentes à educação recebidas pelo governo brasileiro do Comitê da Organização das Nações Unidas, que zela pela implementação da Convenção sobre a Eliminação de Todas as Formas de Discriminação contra a Mulher e pela intensificação dos esforços para acelerar e aprofundar as mudanças culturais. ${ }^{100}$

Dessa forma, é plenamente possível, aceitável e desejável a implementação de uma educação que vise a discussão do gênero enquanto identidade, violência e discriminação, para que os objetivos da Constituição, dos tratados internacionais, da legislação infraconstitucional, dos planos nacionais e Políticas Públicas possam ser cumpridos e efetivamente realizem a transversalidade de uma sociedade preocupada com as reais mazelas vivenciadas hoje: as questões de gênero, etnia, raça, classe e deficiências.

98 ORGANIZAÇÃO DAS NAÇÕES UNIDAS. Currículo de Gênero. Escola sem Machismo.Org. ONU mulheres e $\mathrm{O}$ valente não é violento. Disponível em: http://www.onumulheres.org.br/programasemdestaque/generona-escola/. Acesso em: 20 dez. 2017.

99 NASCIMENTO, M.; ARRUDA, S. Proposta de currículo educativo para o ensino médio sobre promoção da igualdade de gênero entre adolescentes e jovens brasileiros. Escolas - Ensino Médio: Inventário, Currículo E Planos De Aula. ONU mulheres. Gênero na Escola e na Universidade, 2016. Disponível em: http:// www.onumulheres.org.br/programasemdestaque/genero-na-escola/\%3E. Acesso em: 15 dez. 2017. 100 BRASIL. Presidência da República. Secretaria Especial de Políticas para as Mulheres. II Plano Nacional de Políticas para as Mulheres. Op. Cit. 
ISSN 1981-3694

(DOI): $10.5902 / 1981369431721$

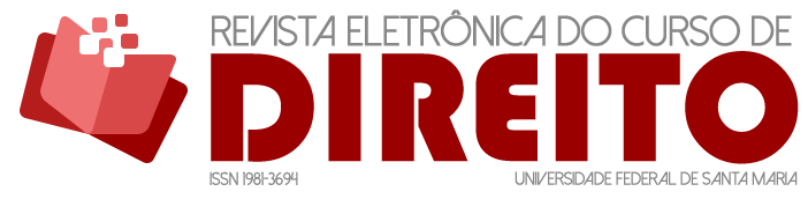

POLÍTICAS PÚBLICAS DE GÊNERO NA EDUCAÇÃO: UMA ANÁLISE PARA O DESENVOLVIMENTO

MIRIAM OLIVIA KNOPIK FERRAZ NICOLAS ADDOR JOSÉ OSÓRIO NASCIMENTO NETO

Além disso, a própria noção de desenvolvimento que o país adotar irá afetar diretamente a seleção de prioridades e a formulação de planos governamentais. A superação das graves desigualdades sociais que são consequência da adoção de um modelo de desenvolvimento que prioriza o mercado ${ }^{101}$ e a visão única da valorização econômica é essencial para a construção de uma sociedade justa e plural.

A criação, implantação, execução, avaliação, e expansão das Políticas Públicas têm o objetivo e a justificativa de combater as causas da privação da liberdade que impedem que cada pessoa desenvolva a capacidade de escolha e do exercício da condição de agente ativo. A discriminação, preconceito, segregação e a valorização da diferença de forma negativa que incentiva as privações, resultam na impossibilidade de os indivíduos poderem escolher e vivenciar a vida que valorizam, pois estão cercados e impedidos pelas mazelas da sociedade.

A percepção dessa deficiência é crucial e, segundo aponta Amartya Sen, está relacionada com o conjunto de fatores que integram o exercício da autonomia das pessoas, como a negação de acesso à educação de qualidade, à participação pública nos diversos espaços e ambientes, dentre outros. Reconhecer a existência dessas privações é um passo para reconhecer que se precisa de ações. A liberdade e a sua expansão são pontos centrais para a concepção de desenvolvimento que se propõe: o desenvolvimento como expansão das liberdades. ${ }^{102}$

Dessa forma, a educação é um fator essencial e basilar para a supressão das privações dos indivíduos e a construção de uma sociedade tolerante e aberta ao diálogo. Somente através e por meio dela é possível conceber o desenvolvimento de uma nação, que se afaste exclusivamente dos parâmetros econômicos, e avalie e busque uma sociedade voltada para a sua evolução social.

\section{CONCLUSÃO}

O Estado brasileiro, dotado de uma política de bem-estar social, deve buscar garantir ao máximo as prerrogativas que garantam ao cidadão possuir plena capacidade. Mesmo se analisado sob uma óptica liberal, o comprometimento em garantir os direitos básicos de liberdade e igualdade fazem com que o Estado possua a responsabilização de promover um tratamento

101 ZAMBAM, N. J. Z.; KUJAWA, H. A. As políticas públicas em Amartya Sen: condição de agente e liberdade social. Revista Brasileira de Direito, Passo Fundo, v. 13, n. 1, p. 60-85, Jan.-Abr. 2017.

102 SEN, Amartya. Desenvolvimento como liberdade. Tradução de Laura Teixeira Motta. São Paulo: Companhia das letras, 2000. 
ISSN 1981-3694

(DOI): $10.5902 / 1981369431721$

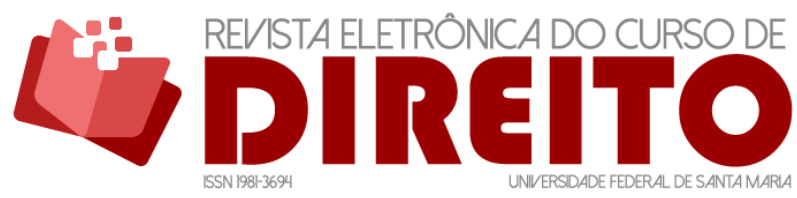

POLÍTICAS PÚBLICAS DE GÊNERO NA EDUCAÇÃO: UMA ANÁLISE PARA O DESENVOLVIMENTO

MIRIAM OLIVIA KNOPIK FERRAZ NICOLAS ADDOR JOSÉ OSÓRIO NASCIMENTO NETO

igualitário entre os gêneros, etnias e quaisquer outras características que aparentam diferenciar um indivíduo. Qualquer que seja a ideologia que a Administração se alinhe, o que se enxerga é a necessidade de incluir as minorias para promover-lhes o respeito a direitos básicos, de maneira vertical e horizontal. Portanto, com base no que foi observado nos questionamentos levantados neste ensaio, é possível concluir que: a garantia de liberdade e igualdade pelo Estado brasileiro não deve se situar somente no aspecto formal, havendo o compromisso de também garantir sua incidência no plano material desses direitos fundamentais. Assim, a existência de ações afirmativas é dotada de uma importância substancial para este processo de superação de preconceitos estigmatizados pela sociedade.

Para isso, a proposta de promover uma mudança por meio de novos alicerces na educação, inclui, para buscar a igualdade de gênero, promover um debate sadio para abordar as desigualdades hoje predominantes, fomentar o respeito mútuo, combater a violência e o assédio e incentivar o respeito a diversidade. Inclusive, verificou-se que o Estado possui o dever-poder de promover a democratização do ensino, o que torna imprescindível, não somente para a promoção da igualdade em sociedade, mas para também garantir o próprio acesso e manutenção ao sistema de educação público, o estudo de gênero visando combater os preconceitos dentro e fora da escola e opondo-se à evasão escolar em razão de marginalização do diferente.

Assim, o estudo de gênero vem discutir a predominância masculina como gênero dominante e os papeis sociais pré-estabelecidos. É forçoso concluir que esse estudo venha promover uma erotização na formação escolar das crianças, que faça alterar a opção sexual ou desrespeitar dogmas religiosos, como defendem o movimento contrário à “ideologia” de gênero. Essa política permite, ao contrário, que os indivíduos possam se manifestar da maneira como são, sem privações, em consonância com os princípios da Constituição e de tratados de direitos humanos.

\section{REFERÊNCIAS}

A BÍBLIA, Uma Janela sobre o mundo bíblico, s.d. Disponível em: http: //www.abiblia.org/ver.php?id=4210. Acesso em: 18 nov. 2017.

ALBUQUERQUE, S. S. de. Educação Infantil: um sonho a ser embalado? Grupo de Estudos em educação infantil e infâncias. Universidade Federal do Rio Grande do Sul, Porto Alegre, 2016. Disponível em: https://www.ufrgs.br/gein/wpcontent/uploads/2016/10/Educa\%C3\%A7\%C3\%A3o-Infantil-um-sonho-a-ser-embalado.pdf>. Acesso em: 10 out. 2017. 
ISSN 1981-3694

(DOI): 10.5902/1981369431721

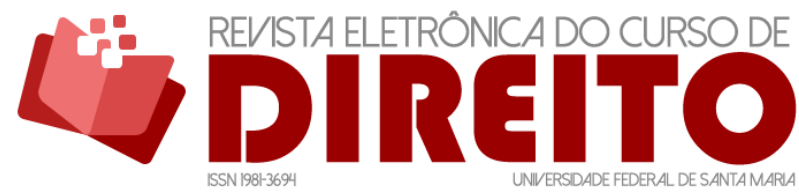

POLÍTICAS PÚBLICAS DE GÊNERO NA EDUCAÇÃO: UMA ANÁLISE PARA O DESENVOLVIMENTO

MIRIAM OLIVIA KNOPIK FERRAZ NICOLAS ADDOR JOSÉ OSÓRIO NASCIMENTO NETO

ALZAMORA REVOREDO, O. La ideologia de género: sus peligros y alcances. Lima: Conferencia Episcopal Peruana, 1998.

AMARAL JÚNIOR, I. P.. Educação para a diferença é um direito: a adequação constitucional das políticas públicas de combate à homofobia nas escolas. Dissertação (Mestrado em Direito) Programa de Pós-Graduação em Direito, Estado e Constituição da Universidade de Brasília. 2017.

BARCELOS, L.C. Educação e desigualdades raciais no Brasil. Cadernos de Pesquisa, n. 86, ago 1993.

BENHABIB, S.; CORNELL, D. Feminismo como crítica da modernidade. Rio de Janeiro: Rosa dos tempos, 1987.

BENTO XVI, Discurso à Cúria Romana na Apresentação de Votos de Feliz Natal. Cidade do Vaticano, 22 de dezembro de 2008. In: JUNQUEIRA, R. D. "Ideologia de Gênero": a invenção de uma categoria polêmica contra os direitos sexuais. In: RAMOS, M. M.; NICOLI, P. A. G.; ALKMIN, G. C. (Orgs.). Gênero, sexualidade e direitos humanos. Perspectivas multidisciplinares. Belo Horizonte: Initia Via, 2017.

BRASIL. Ministério da Saúde. Brasil sem homofobia. Conselho Nacional de Combate à Discriminação, 2004. Disponível em:

http://bvsms.saude.gov.br/bvs/publicacoes/brasil_sem_homofobia.pdf. Acesso em: 18 nov. 2017.

BRASIL, Cidadania e Justiça. Pessoas com deficiência ganham espaço na pauta dos direitos humanos, diz Conade, 2016. Disponível em: http://www.brasil.gov.br/cidadania-ejustica/2016/04/colocamos-o-debate-de-pessoas-com-deficiencia-no-campo-dos-direitoshumanos-diz-presidente-do-conade. Acesso em: 15 dez. 2017.

BRASIL, Ministério da Educação. Plano Nacional de Educação de 2011 -2020. Disponível em: http: //portal.mec.gov.br/index.php?option=com_content\&id=16478\&/temid=1107. P.56. Acesso em: 1 dez. 2017.

BRASIL, Ministério da Educação. Programas e Ações, s.d. Disponível em: http: //portal.mec.gov.br/secretaria-de-educacao-continuada-alfabetizacao-diversidade-einclusao/programas-e-acoes. Acesso em: 23 nov. 2017.

BRASIL, Plano Nacional dos direitos das pessoas com deficiência. Disponível em: https://www.mdh.gov.br/navegue-por-temas/pessoa-comdeficiencia/app/sites/default/files/arquivos/\%5Bfield_generico_imagens-filefielddescription\%5D_0.pdf. Acesso em: 15 dez. 2017.

BRASIL, Política Nacional de Promoção da Igualdade Racial. Disponível em: http://bvsms.saude.gov.br/bvs/publicacoes/politica_nacional_promocao_igualdade_racial.pdf. Acesso em: 15 dez. 2017.

BRASIL, Presidência da República. Secretaria Especial de Políticas para as Mulheres. II Plano

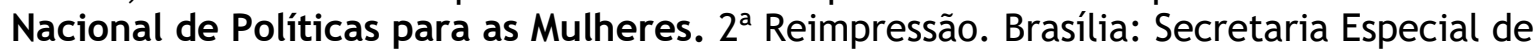
Políticas para as Mulheres, 2008. Disponível em: https://www.mdh.gov.br/assuntos/pnpm/livroii-pnpm-completo09.09.2009.pdf Acesso em: 15 dez.2017. 
BRASIL, Presidência da República. Secretaria Nacional de Políticas para Mulheres. Plano Nacional de Políticas para as Mulheres. Disponível em:

https://www.mdh.gov.br/assuntos/pnpm. Acesso em: 15 dez. 2017.

BRASIL. Secretaria de Governo da Presidência da República. Curso de Gênero, Diversidade e Educação (GDE). Disponível em: https: / /www.mdh.gov.br/sobre/a-secretaria/subsecretaria-dearticulacao-institucional-e-acoes-tematicas/coordenacao-geral-de-programas-e-acoes-deeducacao/genero-e-diversidade-na-escola/curso-genero-e-diversidade-na-escola-gde. Acesso em: 17 out. 2017.

BRASIL. Ministério dos Direitos Humanos. Conselho Nacional de Combate à Discriminação de LGBT. Disponível em: https://www.mdh.gov.br/sobre/participacao-social/cncd-lgbt. Acesso em: 16 jan. 2018.

BRASIL. Ministério dos Direitos Humanos. Pacto nacional de enfrentamento à violência LGBTFóbica. Disponível em: https://www.mdh.gov.br/assuntos/lgbt/programas/pacto-nacionalde-enfretamento-a-violencia-lgbtfobica. Acesso em: 16 jan. 2018.

BRASIL. PARÂMETROS CURRICULARES NACIONAIS: apresentação dos temas transversais: ética/Ministério da Educação. Secretaria da Educação Fundamental. 3. Ed. Brasília: A Secretaria, 2001.

BRASIL. Secretaria Nacional de Políticas Públicas para as Mulheres. Programa Mulher, viver sem violência. Disponível em: https://www.mdh.gov.br/assuntos/violencia/programa-mulher-viversem-violencia. Acesso em: 15 jan. 2018.

BRASIL. Secretaria Nacional de Políticas Públicas para as Mulheres. Resultado do Cumprimento de Metas Institucionais, 2017. Disponível em: https://www.mdh.gov.br/sobre/acoes-eprogramas/1o-2o-e-3o-ciclos-avaliativos-das-metas-avaliativas-2017. Acesso em: 16 jan. 2018.

CANARC, R. L’Église catholique contre “la théorie du genre”: construction d'un objet polémique dans le débat public français contemporains. Synergies Italie, n. 10, 2014.

CANDAU, V. M. F. Educação escolar e cultura(s). Tecnologia Educacional, v. 22, n. 125, jul./ago. 1995, p. 23-28.

CANEN, A. Universos culturais e representações docentes: subsídios para a formação de professores para a diversidade cultural. Educação \& Sociedade, ano XXII, n. 77, dez 2001.

CARVALHO FILHO, J. dos S. Manual de Direito Administrativo. 31. Ed. São Paulo: Atlas, 2017.

CARVALHO, M. P. de. Gênero e trabalho decente: em busca de um referencial teórico. In: BRUSCHINI, C.; BUARQUE DE HOLLANDA, H. (Orgs.) Horizontes plurais: novos estudos de gênero no Brasil. São Paulo: Editora 34/ Fundação Carlos Chagas, 1998.

ÉPOCA. ONU é acusada de permitir abusos sexuais em seus escritórios. Disponível em: https://epocanegocios.globo.com/Mundo/noticia/2018/01/onu-e-acusada-de-permitir-abusossexuais-em-seus-escritorios.html. Acesso em: 19 jan. 2018. 
ISSN 1981-3694

(DOI): $10.5902 / 1981369431721$

FARAH, M. F. S. Gênero e Políticas Públicas. Revista Estudos Feministas. Florianópolis, UFSC, v. 12, n. 1, jan./abr. 2004a. p. 47-71.

FREIRE, N.; HADDAD, F.; RIBEIRO, M. Construindo uma política de educação em gênero e diversidade. In: BARRETO, A.; ARAÚJO, L.; PEREIRA, M. E. (Orgs). Gênero e diversidade na escola: formação de professoras/ES em gênero, orientação sexual e relações étnico-raciais. Livro de Conteúdo. Rio de Janeiro: CEPESC; Brasília: SPM, 2009.

GABARDO, E. Interesse público e subsidiariedade: o Estado e a sociedade civil para além do bem e do mal. Belo Horizonte: Fórum, 2009.

GARBAGNOLI, Sara. "L'ideologia del genere": l'irresistible ascesa di um"invenzione retorica vaticana contro la denaturalizzazione dell"ordine sessuale. AG About Gender, v.3, n.6, 2014, p.250-263.

HUSSON, A. Stop à la rumeur:parlons de genre: GenERe. Genre. Lyon, 2014.

GIDDENS, A.; BECK, U.; LASH, S. Modernização Reflexiva. São Paulo: UNESP, 1997.

HITA, M. G. Gênero, ação e sistema: a reinvenção dos sujeitos. Lua nova, n 43, p.109-131, 1998.

ISTOÉ, Hollywood e o assédio sexual: cresce a lista de acusados. Disponível em: <https://goo.gl/jcggt4>. Acesso em: 19 jan. 2018.

JUNQUEIRA, R. D. "Ideologia de Gênero": a invenção de uma categoria polêmica contra os direitos sexuais. In: RAMOS, M. M.; NICOLI, P. A. G.; ALKMIN, G. C. (Orgs.) Gênero, sexualidade e direitos humanos. Perspectivas multidisciplinares. Belo Horizonte: Initia Via, 2017.

LIMA, A. H. M. O direito humano ao desenvolvimento sob a ótica das minorias de gênero. Dissertação (Mestrado em Desenvolvimento Local) - Universidade Católica Dom Bosco, 2015.

LIRA, I. Sociedade do trabalho e a vida determinada pela Identidade de gênero: por uma perspectiva materialista da condição socioeconômica da comunidade trans. Revista Trabalho Necessário, ano 15, n. 28, 2017.

LOURO, G L. L. Gênero, sexualidade e educação: uma perspectiva pós-estruturalista. 16. ed. Petrópolis: Vozes, 2014.

LÜDKE, M., MEDIANO, Z. Avaliação na escola de $1^{\circ}$ grau: uma análise sociológica. Campinas: Papirus, 1992.

MARIANO, S. A. Incorporação de gênero nas políticas públicas: incluindo os diferentes na cidadania. In: II Seminário Internacional Educação Intercultural, Gênero e Movimentos Sociais, 08 a 11 de abril de 2003, Florianópolis/SC. Disponível em:

http: / / titosena.faed.udesc.br/Arquivos/Artigos_gensex/Genero\%20nas\%20politicas\%20\%20public as.pdf. Acesso em: 15 out. 2017. 
ISSN 1981-3694

(DOI): 10.5902/1981369431721

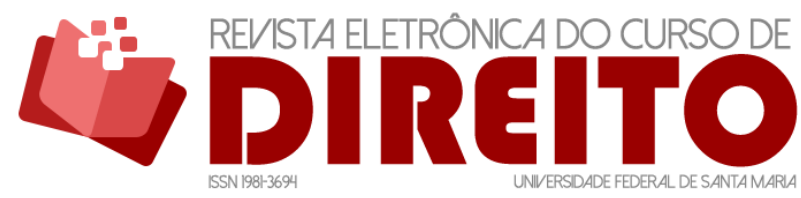

POLITICAS PÚBLICAS DE GÊNERO NA EDUCAÇÃO: UMA ANÁLISE PARA O DESENVOLVIMENTO

MIRIAM OLIVIA KNOPIK FERRAZ NICOLAS ADDOR JOSÉ OSÓRIO NASCIMENTO NETO

MARIZ, Renata. Governo Federal dá calote em vencedores de concurso de redação.O GLOBO. Disponível em: https://oglobo.globo.com/sociedade/educacao/governo-federal-da-calote-emvencedores-de-concurso-de-redacao-21136166. Acesso em: 14 jan. 2018.

MELLO, C. A. B. de. Curso de Direito Administrativo. 31. Ed. São Paulo: Malheiros, 2014.

MELLO, G. N. de. Políticas públicas de educação. Estud. Av., São Paulo, v. 5, n. 13, p. 747, dez.1991.

MEYER, D. E. Gênero e Educação: teoria e política. In: LOURO, G. L; FELIPE, J.; GOELLNER, S. V. (Orgs.). Corpo, gênero e sexualidade: um debate contemporâneo. 9. ed. Petrópolis: Vozes, 2013.

NARTH INSTITUTE, The Alliance (ATCSI) - NARTH Institute Statement on Sexual Orientation Change. Disponível em: <https://www.narth.com/about1>. Acesso em: 15 nov. de 2017.

NASCIMENTO, M.; ARRUDA, S. Proposta de currículo educativo para o ensino médio sobre promoção da igualdade de gênero entre adolescentes e jovens brasileiros. Escolas - Ensino Médio: Inventário, Currículo E Planos De Aula. ONU mulheres. Gênero na Escola e na Universidade. Disponível em: http://www.onumulheres.org.br/programasemdestaque/generona-escola/\%3E. Acesso em: 15 dez. 2017.

NICHOLSON, L. Interpreting gender. Sings: Journal of women in culture and society, Chicago, v.20, n.1, 1994, p.75-105.

ORDEM DOS ADVOGADOS DO BRASIL. Comissão Especial da Diversidade Sexual. Anteprojeto Estatuto da Diversidade Sexual e de Gênero, 2017. Disponível em:

http: / / legis.senado.leg.br/sdleg-getter/documento?dm=7302364\&disposition=inline. Acesso em: 20 dez. 2017.

ORGANIZAÇÃO DAS NAÇÕES UNIDAS. Currículo de Gênero. Escola sem Machismo. ONU mulheres e $O$ valente não é violento, 2016. Disponível em:

http://www.onumulheres.org.br/programasemdestaque/genero-na-escola/. Acesso em: $20 \mathrm{dez}$. 2017.

ORGANIZAÇÃO DAS NAÇÕES UNIDAS. Gênero na escola e na universidade, 2016. Disponível em: http://www.onumulheres.org.br/programasemdestaque/genero-na-escola/. Acesso em: 30 jan. 2018.

OXFORD DICTIONARIES, Genderfluid. Disponível em:

https://www.lexico.com/en/definition/gender-fluid. Acesso em: 10 dez. 2017.

PATERNOTTE, D. “Habemus gender" Autopsie d'une obsession vaticane. In: PIETTE, V.. PATERNOTTE, D.; DUSSEN, S. van der (Dir.). Habemus gender! Autopsie d'une obsession vaticane. Brucelas: EUB, 2016, p.7-22

ROSADO-NUNES, M. J. F. A “ideologia de gênero" na discussão do PNE: a intervenção da hierarquia católica. Horizonte, Belo Horizonte, v.13, n39, jul/dez 2015, p.1237-1260. 
ISSN 1981-3694

(DOI): $10.5902 / 1981369431721$

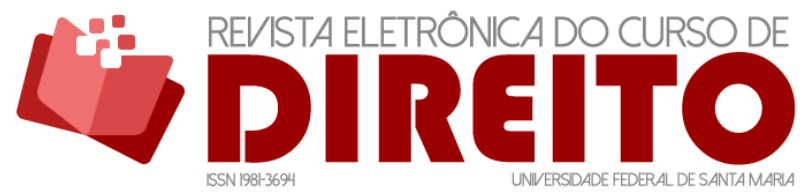

POLÍTICAS PÚBLICAS DE GÊNERO NA EDUCAÇÃO: UMA ANÁLISE PARA O DESENVOLVIMENTO

MIRIAM OLIVIA KNOPIK FERRAZ NICOLAS ADDOR JOSÉ OSÓRIO NASCIMENTO NETO

PONTIFÍCIO CONSELHO PARA A FAMÍLIA. Família, matrimônio e "uniões de fato". Cidade do vaticano, 2000.

SAFFIOTI, H. L.B. Violência de gênero no Brasil contemporâneo. In: SAFFIOTTI, H. l. B.; MUÑOZVARGAS, M. (Orgs.) Mulher brasileira é assim. Rio de Janeiro/ Brasília: Rosa dos Tempos NIPAS/UNICEF, 1994.

SCOTT, J. Prefácio a "Gender and Politics of History". Cadernos Pagu, Campinas, n.3, p.11-27, 1994.

SEN, A. Desenvolvimento como liberdade. Tradução de Laura Teixeira Motta. São Paulo: Companhia das letras, 2000.

SOUSA, L. A. B.; GRAUPE, M. E. Gênero e Políticas Públicas de Educação. In: Anais do III Simpósio Gênero e Políticas Públicas, ISSN 2177-8248 Universidade Estadual de Londrina, 27 a 29 de maio de 2014. Disponível em:

http://www.uel.br/eventos/gpp/pages/arquivos/GT6_L\%C3\%BAcia\%20Aulete\%20B\%C3\%BArigo\%20 de\%20Sousa.pdf Acesso em: 15 nov. 2017.

SOUZA, C. Políticas Públicas: uma revisão da literatura. Sociologias, Porto Alegre, ano 8, n. 16, jul./dez. 2006.

SOWELL, T. Ação afirmativa ao redor do mundo: um estudo empírico sobre cotas e grupos preferenciais. São Paulo: É Realizações, 2016.

VALLE, V. R. L. do. Políticas públicas, direitos fundamentais e controle judicial. Belo Horizonte: Fórum, 2009.

VÁZQUEZ, G. G. H. Gênero não é ideologia: explicando os Estudos de Gênero, 2017. Disponível em: https://www.cafehistoria.com.br/explicando-estudos-de-genero. Acesso em: 15 jan. 2018.

VIANA, N. O que são minorias? Revista Posição. ano 3, v. 3, n. 9, jan./mar. 2016.

VIANNA, C. Gênero, sexualidade e políticas públicas de educação: um diálogo com a produção acadêmica. Pro-Posições, Camipnas, v.23, n.2, p.127-143, maio/ago. 2012.

ZAMBAM, N. J. Z.; KUJAWA, H. A. As políticas públicas em Amartya Sen: condição de agente e liberdade social. Revista Brasileira de Direito, Passo Fundo, v. 13, n. 1, p. 60-85, Jan.-Abr. 2017. 
ISSN 1981-3694

(DOI): $10.5902 / 1981369431721$

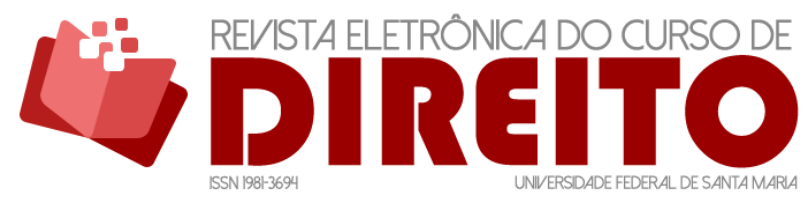

POLÍTICAS PÚBLICAS DE GÊNERO NA EDUCAÇÃO: UMA ANÁLISE PARA O DESENVOLVIMENTO

MIRIAM OLIVIA KNOPIK FERRAZ NICOLAS ADDOR

JOSÉ OSÓRIO NASCIMENTO NETO

Recebido em: 18.03.2018 / Revisões requeridas em: 01.06.2019 / Aprovado em: 14.09.2019 / Publicado em: 09.10.2019

\section{COMO FAZER REFERÊNCIA AO ARTIGO (ABNT):}

FERRAZ, Miriam Olivia Knopik; ADDOR, Nicolas Addor; NASCIMENTO NETO, José Osório. Políticas públicas de gênero na educação: uma análise para o desenvolvimento. Revista Eletrônica do Curso de Direito da UFSM, Santa Maria, RS, v. 14, n. 3, e31721, set./dez. 2019. ISSN 1981-3694. DOI:

http://dx.doi.org/10.5902/1981369431721. Disponível em:

https://periodicos.ufsm.br/revistadireito/article/view/31721 Acesso em: dia mês. ano.

Direitos autorais 2019 Revista Eletrônica do Curso de Direito da UFSM

Editores responsáveis: Rafael Santos de Oliveira e Angela Araujo da Silveira Espindola

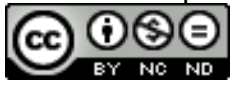

Esta obra está licenciada com uma Licença Creative Commons Atribuição-NãoComercial-SemDerivações 4.0 Internacional.

\section{SOBRE OS AUTORES}

\section{MiRIAM OLIVIA KNOPIK FERRAZ}

Doutoranda em Direito pela PUCPR (bolsista PROSUP). Mestre pela PUCPR. Especialista em Direito Constitucional pela ABDCONST. Pós-graduanda Legal Tech: Direito, Inovação e Start Ups pela PUC Minas. Editora Adjunta da Revista da ABDCONST. Membro Núcleo de Estudos de Pesquisas em Tributação, Complexidade e Desenvolvimento e do Grupo de pesquisa Análise Econômica do Direito da PUCPR. Membro da Comissão de Igualdade Racial e da Verdade da Escravidão Negra da OABPR. Desenvolve pesquisa na área de Direito Constitucional e Direito ao/do Trabalho

\section{NICOLAS ADDOR}

Professor do Curso de Direito, Administração e Ciências Contábeis do Centro Universitário de Araucária e do cursinho preparatório do Concurseiro.com. Mestre em Direito pela Pontifícia Universidade Católica do Paraná (PUCPR) com bolsa de estudos da PROCUC/CAPES. Cursa Especialização em Direito da Tecnologia na Pontifícia Universidade Católica de Minas Gerais. Especialista em Direito Constitucional pela Academia Brasileira de Direito Constitucional (ABDConst). Bacharel em Direito pela Universidade Católica Dom Bosco (UCDB). Participou do programa de iniciação científica da UCDB de 2013 até 2017 como bolsista (Bolsa UCDB e CNPq) e atualmente é colaborador do Grupo de Pesquisa Patrimônio Cultural, Direito e Diversidade (UCDB). Participou do programa de intercâmbio TOP China 2016 promovido pela Santander Universidades como representante discente. Advogado. Fala português, inglês, francês e espanhol. Tem experiência na área de Desenvolvimento Científico, Direito Público e Direito e Tecnologia.

\section{JosÉ OSÓRIO NASCIMENTO NETO}

Advogado. Pós-doutorado em Direito Político e Econômico pela Universidade MACKENZIE, sob supervisão da Professora Dra. e Livre-docente Irene Patrícia Nohara. Doutor e Mestre em Direito Econômico e Social pela PUC Paraná, com estágio de doutoramento na Universidad Carlos III de Madrid - UC3M (bolsista CAPES/PDSE). Especialista em Direito Contemporâneo com ênfase em Direito Público, pela Universidade Candido Mendes do Rio de Janeiro - UCAM/RJ. Graduado em Direito pela PUCPR. Realizou atualização de EaD Docência: Metodologia do Ensino Superior e Metodologia de Pesquisa Científica, pela Fundação Getúlio Vargas do Rio de Janeiro - FGV/RJ. Professor de Teoria da Constituição e Direito Administrativo do Centro Universitário UNIBRASIL. Professor da ESTÁCIO Curitiba, onde Coordena a Iniciação Científica. Professor convidado da Pósgraduação em Direito Administrativo da Universidade POSITIVO. Professor convidado da Escola da Magistratura Federal do Paraná - ESMAFE. Líder do Grupo de Pesquisa "Direito e Políticas Públicas" do UniBrasil. Membro do Núcleo de Pesquisas em Políticas Públicas e Desenvolvimento Humano - NUPED da PUCPR. Membro da Associação Ítalo-brasileira de Professores de Direito Administrativo e Direito Constitucional - AIBDAC. Parecerista da Revista Brasileira de Políticas Públicas (A1), Revista de Direito Brasileira (A1), Revista Veredas do Direito (A1) e Revista do Direito (A2). Tem atividade de extensão e orienta: iniciação científica, monitoria e monografias. Atua e desenvolve pesquisas sobre: Instituições democráticas, regulação estatal e políticas públicas; Governança, escolhas públicas e processos decisórios; Administração Pública, infraestrutura e desenvolvimento; Educação jurídica e metodologia da pesquisa em Direito. 